\title{
Large eddy simulation of REST hypersonic combustor based on dynamic zone flamelet model
}

\author{
Wei Yao ${ }^{1}$ Liu Chen ${ }^{2}$ \\ Key Laboratory of High-Temperature Gas Dynamics, Institute of Mechanics, CAS, Beijing 100190, China \\ School of Engineering Science, University of Chinese Academy of Science, Beijing 100049, China
}

Internal-external coupled full-scale modeling for a rectangular-to-elliptical shapetransition (REST) scramjet under a high flight Mach number of 12 was modeled by Improved Delayed Improved Delayed Detached Eddy Simulation (IDDES) and a Dynamic Zone Flamelet combustion Model (DZFM). The modeling is based on a total cell number of 63.03 million and a $13 \mathrm{~s} / 33 \mathrm{r}$ nonequilibrium hydrogen mechanism. The effect of differential diffusion was investigated for the flow fields, efficiency indices, and thrust performance. A sensitivity analysis of the zone discretion was conducted to select the optimal zone number with acceptable accuracy yet high efficiency. The predicted wall pressure is comparable with the measurements. Detailed analysis of the characteristics of hypersonic flow, reacting species, and combustion was analyzed by using Takeno Flame Index (TFI) and Chemical Explosives Mode Analysis (CEMA), etc.

\section{Introduction}

\begin{abstract}
$\mathrm{M}$ ost of current air-breathing scramjets are designed to operate in the Mach number (Ma) range of 4-8, because of the near-term military demands [1]. However, scramjets designed to operate in Mach numbers above 10 are urgently needed to meet the long-term demands from earth-to-orbit-and-return transportation systems, possibly by using a hybrid launcher combining scramjets inline with other propulsion technologies, e.g., rocket [2]. In the hybrid launcher, the scramjet mode will continue for some a considerable period to contribute some net thrust even after the rocket mode is turned on. Thus there is a Mach number range over which both modes are operational [3]. It is expected that the scramjet can still contribute net thrust during the co-operation mode, rather than becoming a burden of the whole propulsion system too early. "This requirement makes the understanding of hypersonic combustion phenomena as significant as that of supersonic combustion", as stated by Mehta [3] two decades ago. To achieve this goal, a question that must be answered by the propulsion community is that what is the maximum speed a scramjet can still provide the net thrust?

Except for the 10s flight demonstration by the X-43 at Mach 9.68 [4], most of the hypersonic air-breathing vehicles were tested at the low end of the hypersonic range $(\mathrm{Ma}<8)$, while hypersonic scramjets with $\mathrm{Ma} \geq 10$ has yet to be demonstrated in flight. Theoretical analysis by Weber and MacKay [5] was possibly the first to show that the engine efficiency keeps increasing with flight Mach number in the range of 4-7, and the scramjet performs better than the ramjet for Ma> 7 if an isentropic inlet is used. In any multistaged vehicles for access to low Earth orbit (LEO), scramjets can become useful only if the upper limit of their operation can be stretched to Mach 10+ [2]. Scramjets with a rectangular-to-elliptical shape-transition (REST) inlet [6-8], inlet injection technique [9, 10], and an elliptical combustor capable of delivering net thrust at speeds from $\mathrm{Ma}=7.5$ [11], $\mathrm{Ma}=8$ [12], $\mathrm{Ma}=8.7$ [13], $\mathrm{Ma}=10$ [14], and up to 12 [15-17] have been experimentally tested in University of Queensland's T4 Reflected shock tunnel (RST). Numerical studies for uniform-compression and nonuniform-compression scramjets over the flight Mach number range of 7-12 [18]; however, the negative specific impulse was observed for Ma $>11$. The operating limits are expected to be $\mathrm{Ma}=15$ and 10 for hydrogen and hydrocarbon -fueled scramjets [19]. In addition, given the high specific impulse, hydrogen is possibly the only fuel that can delive positive net thrust at near-orbital velocities [20].

At hypersonic speeds with $\mathrm{Ma}=10+$, the long-lasting conflicts between fast mixing, efficient combustion, and drag reduction, do not weaken but instead are becoming more stringent. At the high flight Mach numbers that an accessto-space scramjet might operate at, even short residence time less than $1 / 3$ milliseconds is left for the mixing and subsequent combustion. The chemical dissociations of the oxygen and nitrogen molecules into their atomic form in
\end{abstract}

\footnotetext{
${ }^{1}$ Associate Professor, Institute of Mechanics (CAS), weiyao@imech.ac.cn, AIAA member (Corresponding author).

${ }^{2}$ Graduate student, Institute of Mechanics (CAS).
} 
the incoming air crossflow under high static temperature not only absorb heat from the flow but also considerably reducing the combustion efficiency due to the consumption of available oxygen. The extremely high temperature also tends to suppress the exothermic reactions by shifting the chemical equilibrium status. Due to the aerodynamic heating, the near-wall temperature can easily exceed $2500 \mathrm{~K}$, and the wall heat flux is generally higher than $4 \mathrm{MW} / \mathrm{m}^{2}$, which implies that active cooling or advanced materials are more stringently required to survive long-duration flights at hypersonic speeds. At $\mathrm{Ma}=10+$, most of the thrust produced by the nozzle has been canceled by the inviscid (pressure) and the viscous (skin friction) drag forces. For hypersonic vehicles, more than $50 \%$ of the net drag force is produced by skin friction [21], and further, while about $60 \%$ of the total skin friction drag is produced inside the combustor and nozzle [22].

A sufficient amount of compression must be guaranteed through the hypersonic inlet while minimizing the total pressure loss. A novel inward-turning sidewall-compressed REST scramjet inlet was designed by blending a rectangular capture area to an elliptical combustion chamber using the streamline tracing technique [6], which produces lower viscous drag and lower total pressure loss. However, the axisymmetric geometric makes the flow entering the combustor no longer nonuniform. The REST inlet combined with an elliptical combustor was designed with the flight Mach numbers of 7-12, and dynamic pressure of $50 \mathrm{kPa}$ [16]. It is claimed that overboard flow spillage can keep the inlet self-started under a variety of adverse conditions, e.g., Mach numbers as low as 4 and back pressure ratios as high as 30.3 [23]. In the original design of the REST scramjet, two-stage fuel injections respectively from the inlet and the combustor are combined. The former is used to prolong the fuel residence time as well as to provide radical farming for the downstream fuel burning. However, robust combustion in the inlet may cause unstart. The latter is to reduce skin friction through film cooling and boundary layer combustion. In the modeling, it is observed that the combustor injection ignited by the flame from the inlet injection significantly contributes to the overall combustion efficiency. Complex shock waves mainly originated from the inlet cowl, the $6^{\circ}$ angle transition from the inlet to the combustor, and the combustion injection were observed in the previous modeling of the RESE scramjet [13]. In addition, low-speed bubbles grown from thickened boundary layer around the perimeter of the isolator and swept boundary layer separation inside the isolator were observed in the modeling, while with their formation mechanism, characterization, and role in the mixing poorly understood.

To better understand the complex flow, mixing, and combustion physics inside the REST scramjet, as well as to provide optimization principles, high-resolution modeling the hypersonic combustion process is necessary. The optimization goal of the first priority is to improve the combustion efficiency over $80 \%$, which is estimated to be the minimum requirement to achieve thrust for access-to-space applications [24]. The strong bow shock wave generated by a high injection momentum may cause high entropy production that counterbalances the benefits obtained from a shorter combustor by using the inlet injection. Thus, the equivalence ratio division between the inlet injection and the combustor injection also needs to be optimally determined to make the best use of the pilot ignition while avoiding massive entropy loss. Due to the $6^{\circ}$ angle of attack and the shape transitions, the impingement of complex shock waves on the shear layer and boundary layer will strongly affect the flow structures and the combustion, which needs to be carefully scrutinized.

\section{Physical models and numerical methods}

\section{A. Experimental case}

In this study, the modeled REST scramjet has a desired flight Mach number of 12 and a dynamic pressure of $\mathrm{q}=$ $50 \mathrm{kPa}$, which corresponds to an altitude of $\sim 36 \mathrm{~km}$ and a flight stagnation enthalpy $\mathrm{H}_{0} \approx 7.16 \mathrm{MJ} / \mathrm{kg}$. The modeled geometry, including the planar forebody, as shown in Figure 1, has an entire length of 1,435 mm. The forebody has a length of $500 \mathrm{~mm}$ and is slightly wider than the inlet capture area. The $476.2-\mathrm{mm}$-long inlet section extends from the leading edge of the body to the throat. The lip of the inlet sidewall turns inward and closes completely respectively at $129.3 \mathrm{~mm}$ and $339.6 \mathrm{~mm}$ downstream of the inlet leading edge. The leading edge radii were both ignored since they were expected to have a negligible effect on inlet mass capture and efficiency [25]. The isolator section consists of two parts: the 29.67-mm-long former transiting from the inlet into an elliptic shape, and the 25-mm-long latter with constant-area elliptic shape. The initial width of the inlet is $75 \mathrm{~mm}$, and the final width of the contracting elliptic isolator section is $31.05 \mathrm{~mm}$, with an aspect ratio of 1.76. The total geometric compression ratio of the inlet is 6.61 . The combustor section is connected to the isolator with a 1.25 -mm-deep circumferential backward step. In the modeling, the combustor section is inclined with a $6^{\circ}$ angle to redirect the flow toward the actual vehicle direction. The combustor section consists of a 161-mm-long constant-cross elliptical duct, and a 121-mm-long diverging part at an expansion ratio of $1.6^{\circ}$. The nozzle section has a uniform conic area expansion ratio of 5 .

Both inlet injection and combustion injection are combinedly used. The inlet injection is made of three $45^{\circ}$-inclined 
2-mm-diameter portholes on the backside of the compression surface at $755 \mathrm{~mm}$ downstream of the leading edge. The three inlet injectors are all located at the same streamwise plane with a spacing of $12.5 \mathrm{~mm}$. Five 0.8 -mm-diameter injectors are positioned along the lower-half perimeter at the combustor entrance ( $1015.1 \mathrm{~mm}$ from the leading edge). Among the five injectors, three of them are placed with one centered upon the centerline and the other two on either side with a spacing of $6.75 \mathrm{~mm}$. The remaining two are placed horizontally on either side of the wall. The combustor injectors were inclined $45^{\circ}$ to the local wall normal. The total fuel mass flow rate of $1.75002 \mathrm{~g} / \mathrm{s}$ is split $29 / 71$ between the inlet injection and the combustor injection to achieve a combined global equivalence ratio of $\phi=1.24$, which is calculated accounting for both $\mathrm{O}_{2}$ and $\mathrm{O}$. The test conditions of the air crossflow and the hydrogen stream are summarized in Table 1.

Table 1. Summary of test conditions and corresponding flight conditions

\begin{tabular}{ccc}
\hline Quantity & Test condition & Flight condition \\
\hline $\mathrm{p}(\mathrm{Pa})$ & 1176.6 & 398.66 \\
$\mathrm{U}(\mathrm{m} / \mathrm{s})$ & 3630.2 & 3678.41 \\
$\mathrm{~T}(\mathrm{~K})$ & 386.79 & 243.71 \\
$\boldsymbol{\rho}\left(\mathrm{kg} / \mathrm{m}^{3}\right)$ & 0.010507 & 0.00569 \\
$\mathrm{Ma}$ & 9.183 & 11.75 \\
$\mathrm{q}(\mathrm{kPa})$ & 69.23 & 38.55 \\
$\mathrm{H}_{0}(\mathrm{MJ} / \mathrm{kg})$ & 7.01 & 7.01 \\
$\mathrm{Re}$ & $1.695 \times 10^{6}$ & $1.34 \times 10^{7}$ \\
$\mathrm{Y}_{\mathrm{N} 2}$ & 0.72845 & 0.767 \\
$\mathrm{Y}_{\mathrm{O} 2}$ & 0.18372 & 0.233 \\
$\mathrm{Y}_{\mathrm{NO}}$ & 0.082728 & 0 \\
$\mathrm{Y}_{\mathrm{O}}$ & 0.005102 & 0 \\
$\mathbf{m}_{\mathbf{H}_{\mathbf{2}}, \text { inlet }}(\mathrm{g} / \mathrm{s})$ & 0.502635 & - \\
$\mathbf{m}_{\mathbf{H}_{\mathbf{2}}, \mathbf{c o m b u s t o r} \mathbf{H} 2 \text { inlet }}(\mathrm{g} / \mathrm{s})$ & 1.246795 & - \\
$\mathbf{T}_{\mathbf{0}, \mathbf{H}_{\mathbf{2}}}(\mathrm{K})$ & 298 & - \\
$\mathbf{M a}_{\mathbf{H}_{\mathbf{2}}}$ & 1.0 & - \\
\hline
\end{tabular}

(a)

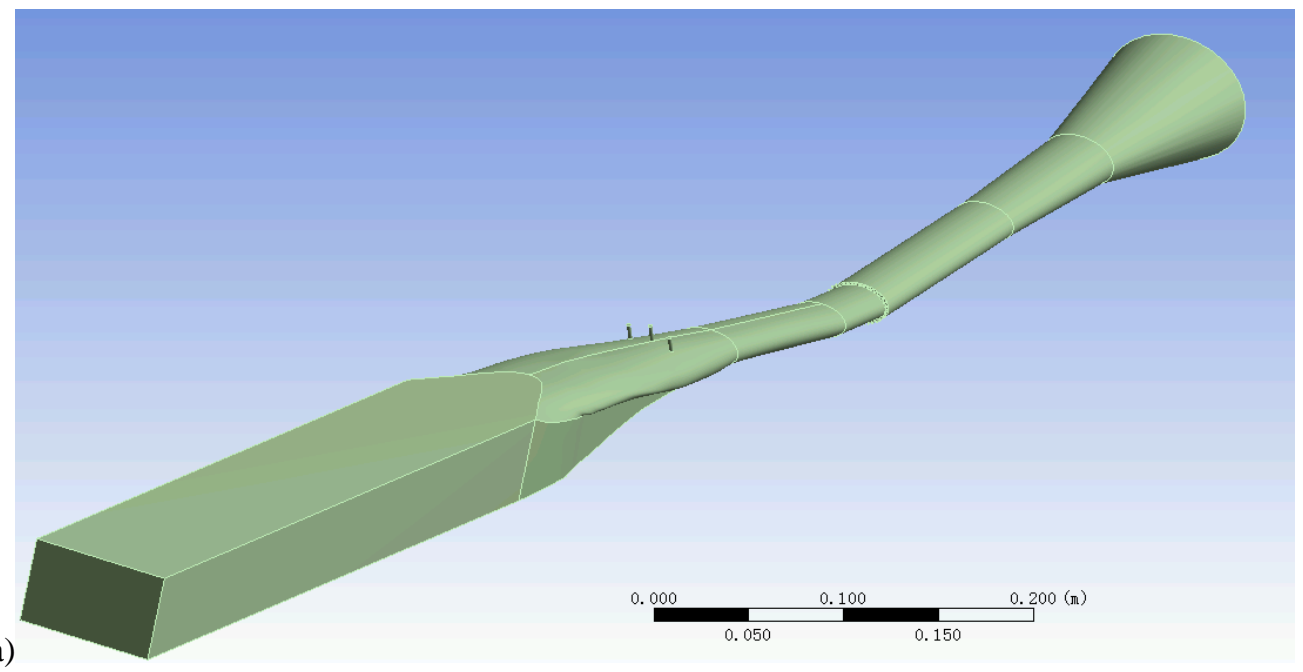




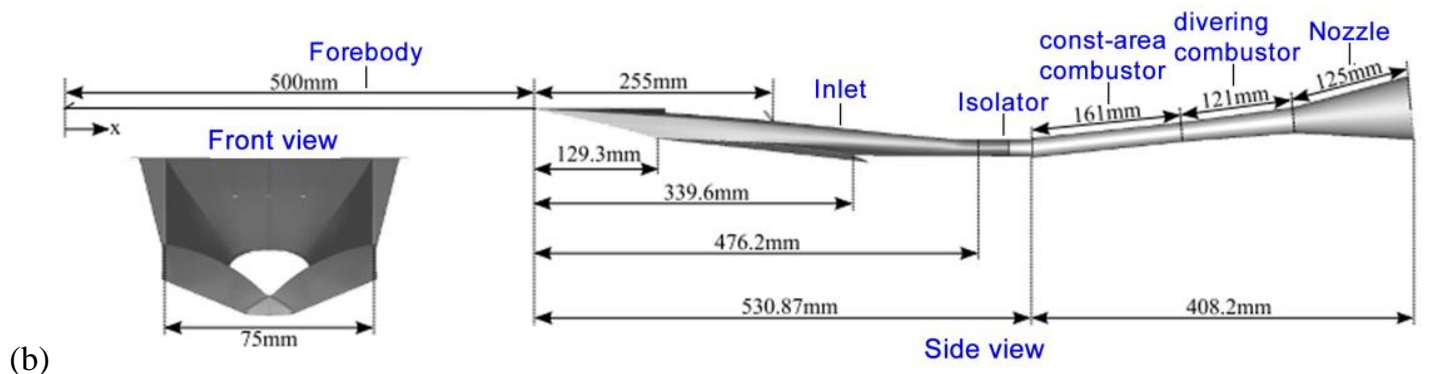

Figure 1. (a) Geometry and (b) dimensions of the REST scramjet with planner forebody

The domain is meshed by Immersed Boundary (IB) CutCell method [26] with a total of $63 . s 03$ million unstructured cells, with a denser distribution clustering around the injectors, as shown in Figure 2. The maximum cell size is 0.8 $\mathrm{mm}$ and a minimum of $50 \mu \mathrm{m}$. A near-wall inflation layer with 13 prism layers and a total thickness of $1 \mathrm{~mm}$ is attached to the chamber wall to ensure that the first near-wall cell located in a nondimensional wall distance $\mathrm{y}^{*}<1$. High-quality uniform hexahedral grid cells for most of the domain, while tetrahedron, wedge, or pyramid cells filled only in large-curvature regions. Mesh quantity analysis shows that 90.7 vol\% of the domain is meshed by hexahedral cells, cells in $95.8 \%$ of the domain volume have skewness less than 0.05 , and cells in $94.2 \%$ of the domain volume have orthogonal quality larger than 0.95 .

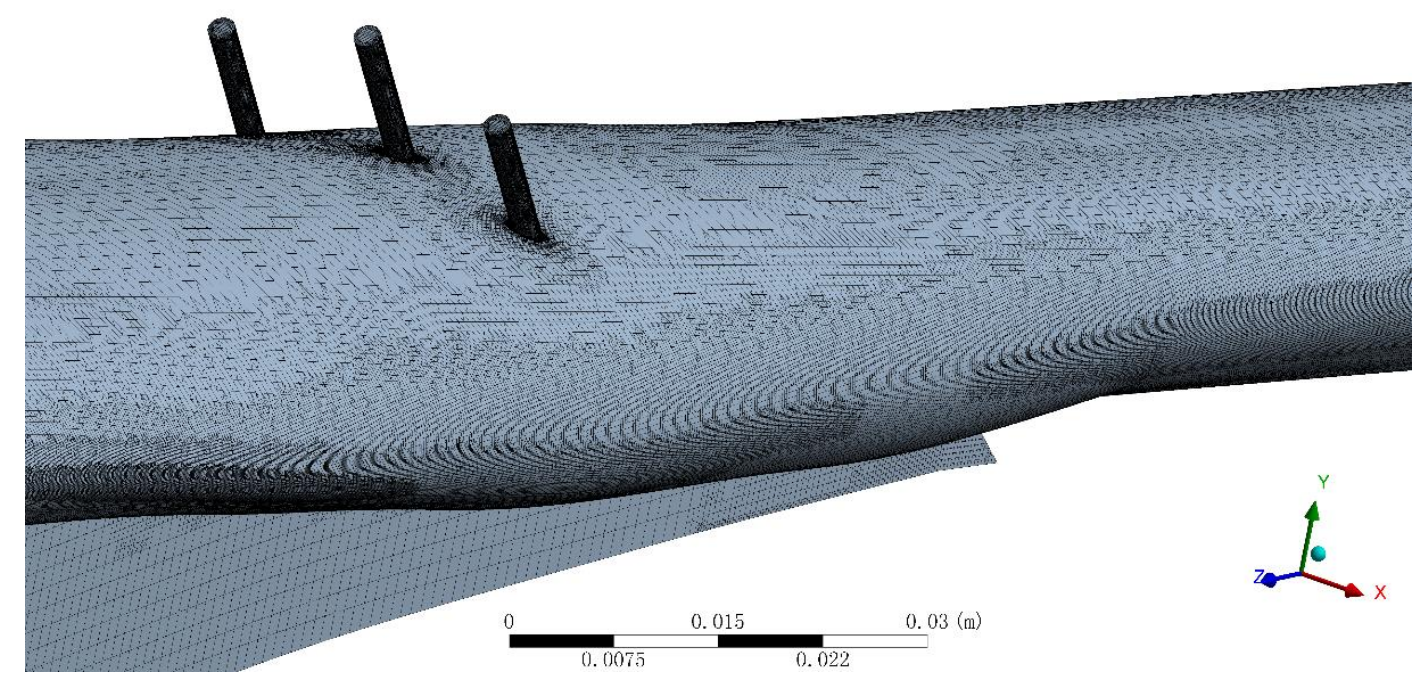

Figure 2. Mesh clustering around the inlet injectors

\section{B. Governing equations with dynamic zone flamelet model (DZFM)}

The unsteady and three-dimensional Favre-averaged compressible reactive Navier-Stokes equations (rNSE) are solved for a set of conservative variables $\left(\bar{\rho}, \widetilde{\mathrm{u}}_{i}, \widetilde{\mathrm{H}}_{t}, \widetilde{\mathrm{Y}}_{\alpha}\right)[27,28]$,

$$
\begin{aligned}
& \frac{\partial \bar{\rho}}{\partial \mathrm{t}}+\frac{\partial \bar{\rho} \widetilde{\mathrm{u}}_{\mathrm{j}}}{\partial \mathrm{x}_{\mathrm{j}}}=0 \\
& \frac{\partial \bar{\rho} \widetilde{\mathrm{u}}_{\mathrm{i}}}{\partial \mathrm{t}}+\frac{\partial \bar{\rho} \widetilde{\mathrm{u}}_{\mathrm{j}} \widetilde{\mathrm{u}}_{\mathrm{i}}}{\partial \mathrm{x}_{\mathrm{j}}}+\frac{\partial \overline{\mathrm{p}}}{\partial \mathrm{x}_{\mathrm{i}}}-\frac{\partial \tilde{\mathrm{i}}_{\mathrm{ij}}}{\partial \mathrm{x}_{\mathrm{j}}}=-\frac{\partial \mathrm{\tau}_{\mathrm{ij}}}{\partial \mathrm{x}_{\mathrm{j}}} \\
& \frac{\partial \bar{\rho} \widetilde{\mathrm{H}}_{\mathrm{t}}}{\partial \mathrm{t}}+\frac{\partial \bar{\rho} \widetilde{\mathrm{u}}_{\mathrm{j}} \widetilde{\mathrm{H}}_{\mathrm{t}}}{\partial \mathrm{x}_{\mathrm{j}}}-\frac{\partial}{\partial \mathrm{x}_{\mathrm{j}}}\left(\bar{\rho} \mathrm{D}_{\mathrm{T}} \frac{\partial \widetilde{\mathrm{H}}_{\mathrm{t}}}{\partial \mathrm{x}_{\mathrm{j}}}+\sum_{\alpha=1}^{\mathrm{L}} \bar{\rho} \mathrm{D}_{\alpha} \frac{\partial \widetilde{\mathrm{Y}}_{\alpha}}{\partial \mathrm{x}_{\mathrm{j}}} \widetilde{\mathrm{H}}_{\alpha}\right)-\frac{\partial \overline{\mathrm{p}}}{\partial \mathrm{t}}-\frac{\partial \widetilde{\mathrm{j}}_{\mathrm{j}} \tilde{\mathrm{i}}_{\mathrm{ij}}}{\partial \mathrm{x}_{\mathrm{j}}}=-\frac{\partial \Psi_{\mathrm{T}, \mathrm{j}}}{\partial \mathrm{x}_{\mathrm{j}}} \\
& \underbrace{\frac{\partial \bar{\rho} \widetilde{Y}_{\alpha}}{\partial \mathrm{t}}+\frac{\partial \bar{\rho} \widetilde{u}_{\mathrm{j}} \widetilde{\mathrm{Y}}_{\alpha}}{\partial \mathrm{x}_{\mathrm{j}}}-\frac{\partial}{\partial \mathrm{x}_{\mathrm{j}}}\left(\bar{\rho} \mathrm{D}_{\alpha} \frac{\partial \widetilde{\mathrm{Y}}_{\alpha}}{\partial \mathrm{x}_{\mathrm{j}}}\right)=-\frac{\partial \Psi_{\alpha, \mathrm{j}}}{\partial \mathrm{x}_{\mathrm{j}}}}_{\text {not solved }} \\
& \frac{\partial \bar{\rho} \tilde{\xi}}{\partial \mathrm{t}}+\frac{\partial \bar{\rho} \widetilde{\mathrm{u}}_{\mathrm{j}} \tilde{\xi}}{\partial \mathrm{x}_{\mathrm{j}}}-\frac{\partial}{\partial \mathrm{x}_{\mathrm{j}}}\left(\bar{\rho} \mathrm{D}_{\alpha} \frac{\partial \tilde{\xi}}{\partial \mathrm{x}_{\mathrm{j}}}\right)=-\frac{\partial \Psi_{\xi, \mathrm{j}}}{\partial \mathrm{x}_{\mathrm{j}}} \\
& \widetilde{\xi^{\prime \prime 2}}=C_{v a r} \Delta^{2}\left(\frac{\partial \tilde{\xi}}{\partial \mathrm{x}_{\mathrm{j}}} \frac{\partial \tilde{\xi}}{\partial \mathrm{x}_{\mathrm{j}}}\right)
\end{aligned}
$$




$$
\begin{gathered}
\rho_{\eta} \frac{\partial \mathrm{Q}_{\alpha}}{\partial \mathrm{t}}+\left\langle\rho \mathrm{u}_{\mathrm{j}} \mid \eta\right\rangle_{\text {zone }} \frac{\partial \mathrm{Q}_{\alpha}}{\partial \mathrm{x}_{\mathrm{j}}}=\rho_{\eta} \frac{\mathrm{D}_{\alpha}}{\mathrm{D}_{\xi}}\langle\chi \mid \eta\rangle_{\text {zone }} \frac{\partial^{2} \mathrm{Q}_{\alpha}}{\partial \eta^{2}}+\rho_{\eta}\left(\frac{\mathrm{D}_{\alpha}}{\mathrm{D}_{\xi}}-1\right) \mathrm{M}_{\eta} \frac{\partial \mathrm{Q}_{\alpha}}{\partial \eta}+\rho_{\eta}\left\langle\mathrm{W}_{\alpha} \mid \eta\right\rangle \\
\overline{\mathrm{p}}=\bar{\rho} \mathrm{RT} \\
\widetilde{\mathrm{H}}_{\mathrm{t}}=\widetilde{\mathrm{H}}+\frac{1}{2} \widetilde{\mathrm{u}}_{\mathrm{i}} \tilde{\mathrm{u}}_{\mathrm{i}}=\widetilde{\mathrm{H}}^{0}+\int_{0}^{\mathrm{T}} \mathrm{C}_{\mathrm{p}} \mathrm{dT}+\frac{1}{2} \widetilde{\mathrm{u}}_{\mathrm{i}} \widetilde{\mathrm{u}}_{\mathrm{i}}
\end{gathered}
$$

Here the bar "_" and the tilde " $\sim$ " represent averaged and Favre-averaged quantities respectively, $t$ denotes the time, $\mathrm{x}_{\mathrm{i}}$ is the Cartesian coordinate in direction $i, \bar{\rho}$ is the density, $\mathrm{u}_{i}$ and $\tilde{\mathrm{u}}_{i}$ are the velocity component in the $\mathrm{x}_{\mathrm{i}}$ direction (spatial dimension $i=1,2,3), \overline{\mathrm{p}}$ is the pressure, $\tilde{\tau}_{\mathrm{ij}}$ is the viscous stress tensor, $\widetilde{\mathrm{H}}_{\mathrm{t}}=\widetilde{\mathrm{H}}+0.5 \tilde{\mathrm{u}}_{\mathrm{i}}^{2}$ is the total absolute enthalpy obtained as the sum of the absolute enthalpy $\widetilde{\mathrm{H}}$ and the resolved kinetic energy, the absolute enthalpy $\widetilde{\mathrm{H}}$ is calculated as the sum of the formation enthalpy $\widetilde{\mathrm{H}}^{0}$ at standard reference state and the sensible enthalpy change from the reference temperature to $T$; $\widetilde{Y}_{\alpha}$ is the mass fraction of species $\alpha(\alpha=1, \ldots, L$, with $L$ the total species number); the specific heat $C_{p}$ is a function of species concentrations and temperature; $\bar{\omega}_{\alpha}$ is the averaged mass production rate of chemical species $\alpha$ in the unit of $\mathrm{kg} \cdot \mathrm{m}^{-3} \cdot \mathrm{s}^{-1}, \mathrm{~W}_{\alpha}$ denotes the reaction rate with unit $\mathrm{s}^{-1} ; \mathrm{D}_{\alpha}$ is mixture-averaged mass diffusivity of species $\alpha, D_{\xi}$ represents the mean mixture diffusivity, $\mathrm{D}_{\mathrm{T}}$ is the thermal diffusivity, $\widetilde{T}$ is the temperature; $\mathrm{R}=\mathrm{R}_{\mathrm{u}} / \mathrm{W}$ is the gas constant, $\mathrm{R}_{\mathrm{u}}=8.314 \mathrm{~J} \cdot \mathrm{mol}^{-1} \cdot \mathrm{K}^{-1}$ is the universal gas constant, $\mathrm{W}=$ $\left(\sum_{\alpha=1}^{\mathrm{L}} \mathrm{Y}_{\alpha} / \mathrm{W}_{\alpha}\right)^{-1}$ is the molar weight of the multicomponent mixture; the local filter width, $\Delta$, serves as the length scale of the subgrid turbulence.

To alleviate the huge computational cost in turbulent combustion modeling, the dynamic zone flamelet model (DZFM) [29] was adopted in this study. The main principle of DZFM is decoupling the turbulence-chemistry interaction (TCI) zone by zone, through dynamically dividing the whole combustion field into a finite number of flamelet zones. The turbulence-influenced thermochemical profile in each zone is represented by a local flamelet, which evolves according to the spatial exchange with its neighbors, chemical reactions controlled by representative temperature, and differential diffusion in the mixture fraction space. Both the zone division and its representative flamelet are dynamically updated for better representing the local chemical status. Through adapting to the evolution of flow fields, DZFM allows a better local statistical homogeneity and diminishes the redistribution effect of conditional variances. DZFM has been previously successfully applied to the modeling of a kerosene-fueled scramjet [30], a $\mathrm{GH}_{2} / \mathrm{GO}_{2}$ jet flame in a single-element rocket combustor [31], and a supersonic hydrogen jet flame [29].

In DZFM, the zone flamelet equation, Eq. (7) is solved instead of the conventional species equation, Eq. (4). The conditional species mass fraction $Q_{\alpha}$ is related to the conventional unconditional species mass fraction $Y_{\alpha}$ as,

$$
\mathrm{Y}_{\alpha}(\mathrm{x}, \mathrm{t})=\mathrm{Q}_{\alpha}(\mathrm{\eta}=\xi(\mathrm{x}, \mathrm{t}), \mathrm{x} \in \text { zone, } \mathrm{t})+\mathrm{Y}_{\alpha}^{\prime}(\mathrm{x} \in \text { zone, } \mathrm{t})
$$

where $\eta$ is the sampling variable in mixture fraction space, $x$ represents the physical coordinate, $x \in$ zone indicates that the conditional average is confined within the zone. Here, $Y_{i}^{\prime}$ represents the deviation of instantaneous value from the conditional average within the current zone. Certainly, it has $\left\langle Q_{i}^{\prime}\right| \eta, x \in$ zone $\rangle=0$, and the zone-averaged $\left\langle\mathrm{Q}_{\mathrm{i}}^{\prime}\right\rangle_{\text {zone }}=\int\left\langle\mathrm{Q}_{\mathrm{i}}^{\prime}\right| \eta, \mathrm{x} \in$ zone $\rangle \mathrm{P}(\eta) \mathrm{d} \eta=0$, with $\mathrm{P}(\eta)$ the probability density function (PDF) describing the distribution of instantaneous $\xi$ within the zone. Here, the $\beta$-function PDF is used because of its continuous shape for integration and the implication of $\delta$-function in its expression. $P(\eta)$ is given as a function of the mean mixture fraction $\tilde{\xi}$ and its variance $\widetilde{\xi^{\prime 2}}$. Favre mean equations for $\tilde{\xi}$ is solved from Eq. (5), while $\widetilde{\xi^{\prime 2}}$ is calculated by the algebraic gradient model as Eq. (6) [32]. Then the unconditional species mass fractions $\widetilde{Y_{\alpha}}$ are recovered by PDF weighted integration,

$$
\widetilde{Y}_{l}=\int Q_{i} P(\eta) d \eta
$$

A statistical approach is used to obtain the conditional temperature, which controls the reaction progress in each conditional bin. Note that the temperature $\widetilde{T}$ is reversely obtained given $\widetilde{H}$ and $\widetilde{Y_{l}}$, rather than from the integration of the conditional temperature, to better account for the compressibility effect in supersonic combustion. As seen, unlike the traditional coupling between CFD and CMC, only the conditional mass fraction is returned for the PDF integration.

According to the Stokes' hypothesis which ignoring the bulk viscosity, the shear-stress tensor for a Newtonian fluid is calculated as:

$$
\tilde{\tau}_{i j}=\bar{\rho} v(\widetilde{T})\left(2 \tilde{S}_{i j}-\frac{2}{3} \delta_{i j} \widetilde{S}_{k k}\right)
$$

where $v$ is a temperature-dependent kinetic viscosity, and the strain-rate tensor of the resolved scales is calculated as:

$$
\widetilde{\mathrm{S}}_{\mathrm{ij}}=\frac{1}{2}\left(\frac{\partial \widetilde{\mathrm{u}}_{\mathrm{i}}}{\partial \mathrm{x}_{\mathrm{j}}}+\frac{\partial \widetilde{\mathrm{u}}_{\mathrm{j}}}{\partial \mathrm{x}_{\mathrm{i}}}\right)
$$

The thermodiffusion (Soret effect), barodiffusion, and mass-driven diffusion of heat (Dufour effect), SGS species diffusive flux, SGS energy diffusive flux, SGS viscous dissipation are all ignored in Eqs. (3)-(4). 
The turbulent Reynolds stresses $\left(\tau_{\mathrm{ij}}\right)$ and turbulent fluxes $\left(\Psi_{\mathrm{T}, \mathrm{j}}\right.$ and $\left.\Psi_{\alpha, \mathrm{j}}\right)$ in Eqs. (2) (5) are unclosed, and both require specific modeling. The Reynolds stress defined as $\tau_{i j}=\bar{\rho}\left(\widetilde{u_{1} \widetilde{u}_{j}}-\widetilde{u}_{i} \tilde{u}_{j}\right)$ is modeled by the Boussinesq eddy viscosity hypothesis, where the Reynolds stresses are also taken to be proportional to $\tilde{S}_{\mathrm{ij}}$,

$$
\tau_{\mathrm{ij}}=\underbrace{\left(\tau_{\mathrm{ij}}-\frac{1}{3} \delta_{\mathrm{ij}} \tau_{\mathrm{kk}}\right)}_{\text {deviatoric }}+\underbrace{\frac{1}{3} \delta_{\mathrm{ij}} \tau_{\mathrm{kk}}}_{\text {isotropic }}=-\bar{\rho} v_{\mathrm{t}}\left(2 \tilde{\mathrm{S}}_{\mathrm{ij}}-\frac{2}{3} \delta_{\mathrm{ij}} \tilde{\mathrm{S}}_{\mathrm{kk}}\right)+\frac{2}{3} \delta_{\mathrm{ij}} \mathrm{k}_{\mathrm{t}}
$$

Here $v_{\mathrm{t}}$ is the eddy viscosity given by a specified turbulence model that will be described in the following section, $\mathrm{k}_{\mathrm{t}}$ is the unresolved turbulent kinetic energy.

The turbulent enthalpy flux term $\Psi_{T, j}=\bar{\rho}\left(\widetilde{\mathrm{u}_{\mathrm{j}} \mathrm{H}_{\mathrm{t}}}-\widetilde{\mathrm{u}}_{\mathrm{j}} \widetilde{\mathrm{H}}_{\mathrm{t}}\right)$ is modeled by the gradient diffusion assumption as

$$
\Psi_{\mathrm{T}, \mathrm{j}}=-2 \bar{\rho} \frac{v_{\mathrm{t}}}{\operatorname{Pr}_{\mathrm{t}}} \frac{\partial \widetilde{\mathrm{H}}_{\mathrm{t}}}{\partial \mathrm{x}_{\mathrm{j}}}
$$

where $\operatorname{Pr}_{t}$ is the turbulent Prandtl number. The turbulent species diffusion term $\Psi_{\alpha, j}=\bar{\rho}\left(\widetilde{\mathrm{u}_{\mathrm{J}} \mathrm{Y}_{\alpha}}-\widetilde{\mathrm{u}}_{\mathrm{j}} \widetilde{\mathrm{Y}}_{\alpha}\right)$ is also modeled using the gradient diffusion assumption as

$$
\Psi_{\alpha, j}=-2 \bar{\rho} \frac{v_{\mathrm{t}}}{\mathrm{Sc}_{\mathrm{t}}} \frac{\partial \widetilde{\mathrm{Y}}_{\alpha}}{\partial \mathrm{x}_{\mathrm{j}}}
$$

where $\mathrm{Sc}_{\mathrm{t}}$ is the turbulent Schmidt number. In this study, unity Prandtl and Schmidt numbers are assumed.

\section{Turbulence closure, property modeling, and solver details}

It is well known that the total computational cost of DNS (Direction Numerical Simulation) depends on the product of the cell numbers and the number of time-steps, hence to $\mathrm{Re}^{11 / 4}$. For wall-bonded flows, such dependence is even stricter. To maintain a constant nondimensional wall grid spacing, $\Delta \mathrm{y}_{\mathrm{n}}^{+}=\Delta \mathrm{y}_{\mathrm{n}} \mathrm{u}_{\tau} / \nu$, the required grid number in the wall-normal direction $n$ is,

$$
\mathrm{N}_{\mathrm{i}}=\frac{\mathrm{L}}{\Delta \mathrm{y}_{\mathrm{n}}}=\frac{\mathrm{L}}{\Delta \mathrm{y}_{\mathrm{n}}^{+} v / \mathrm{u}_{\tau}} \sim \mathrm{Re}^{1-\zeta / 2}
$$

where the friction velocity $\mathrm{u}_{\tau}=\left(\tau_{\mathrm{w}} / \rho\right)^{1 / 2}=\left(0.5 \mathrm{C}_{\mathrm{f}} \mathrm{U}^{2}\right)^{1 / 2}, \tau_{\mathrm{w}}$ is the viscous stress on the wall, $U$ is the outer velocity, the friction coefficient is empirically correlated to the Reynolds number as $\mathrm{C}_{\mathrm{f}} \sim \mathrm{Re}^{-\zeta}$ with $\zeta \approx 0.2-0.25$. Assuming a roughly constant grid aspect ratio, the total number of grid points in the boundary layer is proportional at least to $\mathrm{Re}^{2.6}$. Similarly, the requirement of time steps for the boundary layer modeling is also proportional to $\operatorname{Re}^{1-\zeta / 2}$, hence the total cost scales approximately as $\mathrm{Re}^{3.5}$. As seen, for hypersonic flows typically with $\mathrm{Re}>5 \times 10^{5}$, the resolving of the boundary layer would require a major effort even with high-performance supercomputers. A compromise way is to model the boundary layer using RANS (Reynolds Averaged Navier Stokes) model while resolving the internal flow by LES (Large Eddy Simulation) model.

Hence in this study, the turbulence closure is modeled by Improved Delayed Improved Delayed Detached Eddy Simulation (IDDES) [33] based on the background RANS model one-equation Spalart-Allmaras model [34] to reduce the huge computational cost in modeling the wall boundary layer as well retain LES accuracy in the internal domain. In IDDES, the near-wall region is resolved by traditional RANS modeling, and the outer flow region is treated with LES, with a smooth transition between the two regions. Near the wall, the IDDES length scale is determined by both the local cell sizes and the off-wall distance, and a shielding function is used to adjust the length scale to avoid the mismatch of the boundary layer edge due to excessively low subgrid viscosity. Such a treatment ensures that the boundary layer is fully covered by the RANS mode independent of the mesh distribution near the wall since the boundary layer thickness cannot be determined in prior. As mentioned before, the effect of turbulent fluctuation on the turbulent reaction rate has been accounted for by the DZFM model, assuming $\beta$-function PDF (probability density function) distributions of reacting scalars.

The combustion chemistry and fluid properties are simulated based on a 13-species, 33-reaction mechanism of Jachimowski [35], whose prior and updated versions have been previously applied in hypersonic combustion modelings and exhibit good agreements with the experimental data [9, 15, 36]. Accurate evaluation of fluid properties is crucial to reproduce the flow behaviors. Thermally perfect gas behavior was used as described in Eq.(18). The thermodynamic and transport properties of the gas mixture, such as absolute enthalpy, specific heat, thermal conductivity, viscosity, thermal and mass diffusivities are calculated using the open-source chemical kinetics packageII [37] based on the JANAF (Joint Army-Navy-Air Force)-format thermochemical database [38] and a CHEMKINformat transport database. The viscosity, specific heat and conductivity are all assumed independent of pressure and only depend on temperature. The mixture-averaged viscosity and thermal conductivity are calculated using the modified Wilke's law [39] and the combination averaging, respectively. The mixture thermal diffusivity is then calculated based on the conductive and specific heat. Mixture-averaged mass diffusivities are used, and the mass conservation is achieved by setting the nitrogen as inert gas, whose mass fraction is computed by subtracting the sum of the remaining mass fractions from unity. 
The computation is performed by an OpenFOAM [40] based compressible reacting flow solver Amber (formerly AstroFoam), which adopts the low-dissipative hybrid scheme [41] combining the dissipative Kurganov-Tadmor scheme [42] with the nondissipative central scheme [43]. The AstroFoam was firstly validated for various frozen flows, including the canonical shock tube problem, forward step flow, hypersonic flow over a biconic, and supersonic jets [44-51], and then applied to various scramjet combustor cases [52-58] to examine its accuracy and robustness in the modeling of complex supersonic combustion.

\section{Results and discussion}

Figure 3 compares the predicted pressure profiles on the bodyside and cowlside by DZFM with the experimental measurements and the previous prediction by using an equilibrium combustion model [16]. For the bodyside, both the current and previous predictions exhibit double peaks. The measured peak value at $\mathrm{x}=1.08 \mathrm{~m}$ was slightly underpredicted. At around $\mathrm{x}=0.89 \mathrm{~m}$, there is a secondary peak caused by the reflected shock wave of the bow shock wave arisen by the inlet injection. Whereas in the previous prediction [16], the reflected shock wave impinges on the bodyside at a more downstream location $\mathrm{x}=0.96 \mathrm{~m}$. The pressure oscillations around $\mathrm{x}=0.75 \mathrm{~m}$ and $1.03 \mathrm{~m}$ are due to the disturbances by the inlet injection and the step between the isolator and the combustor, while the pressure oscillation at $\mathrm{x}=0.58 \mathrm{~m}$ is due to the geometric transition from the forebody to the inlet. The pressure agrees with the measurement much better in the diverging combustor and nozzle sections after $\mathrm{x}=1.18 \mathrm{~m}$. For the cowlside, the current predicted pressure profile matches the measurements better, especially for the combustor and nozzle sections after $\mathrm{x}=1.1 \mathrm{~m}$. The pressure rises in the inlet section are due to the reflected oblique shock waves.

The predictions without differential diffusion effect, i.e., with $\mathrm{D}_{\alpha}=\mathrm{D}_{\xi}$ in Eq. (7), are also present in Figure 3. The diffusivity of hydrogen is one order of magnitude higher than the air mixture under the same condition; thus, the unity Lewis assumption tends to reduce the mixing efficiency and correspondingly the momentum exchange, which implies a less pressure drop as indicated in Figure (a). Due to the higher pressure in the boundary layer, the disturbance by the fuel injection is less obvious. The peak pressure is slightly higher without differential diffusion, but the pressure in the divergent combustor and the nozzle is almost identical to the one with differential diffusion since the hydrogen fuel has been completely mixed. For the cowlside, the stronger interaction between the incoming hypersonic flow and the unmixed fuel stream causes more intense oblique shock waves, and higher pressure rises in the inlet and isolator, as shown in Figure 3 (b). Similarly, the influence of differential diffusion on the pressure is unobvious in the combustor and nozzle since where complete mixing has been achieved.
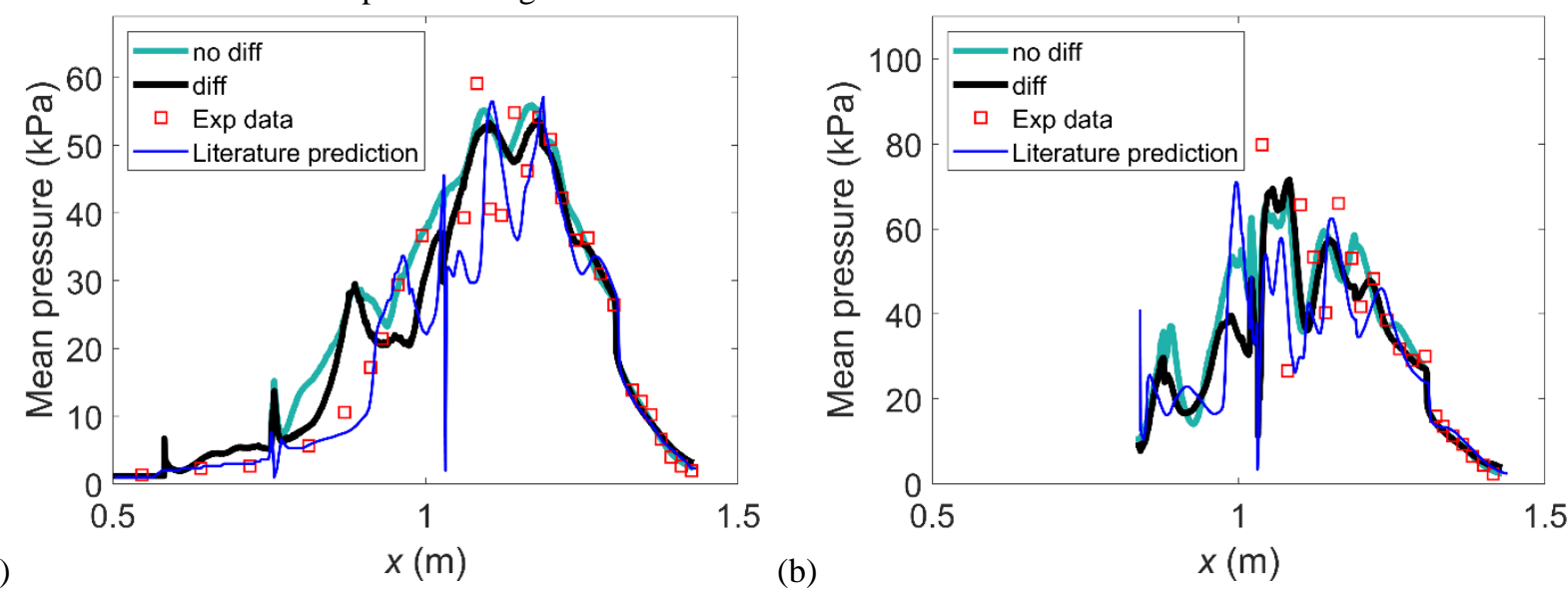

Figure 3. Mean pressure distribution on the (a) bodyside and (b) cowlside

Figure 4 shows the flow fields predicted by the DZFM model with and without differential diffusion effect, respectively. From Figure 4 (a) and (b), the high pressure (above $6 \mathrm{KPa}$ ) mainly occurs inside the constant-area combustor and the front part of the diverging combustor. Without differential diffusion, the disturbance of the incoming flow by the inlet fuel injection is stronger; thus, the pressure raised by the bow shock wave and the subsequent reflected shock waves inside the inlet and isolator is remarkably higher. Part of the high-pressure region even moves upstream to the isolator. The mass capture of the engine in the current prediction is $57 \mathrm{~g} / \mathrm{s}$ with differential diffusion, and $55 \mathrm{~g} / \mathrm{s}$ without differential diffusion, both are close to the $59.35 \mathrm{~g} / \mathrm{s}$ in the previous prediction [16]. It is assumed that the inlet injection does not affect inlet mass capture [16], however when a sufficient pressure rise occurs near the cowl inner margin as in Figure 4 (b), the influence on the mass capture does exist though small. To minimize 
the influence of inlet injection on the mass capture, a slight moving towards the downstream can be made in the port location. From the temperature contours in Figure 4 (c)-(d), it is clear that the fuel begins flowing along the surface, then diffuses through the boundary layer toward the freestream. The inlet injection remains a near $10-\mathrm{cm}$ long trail from the injector port before being visually diffused. The high temperature and pressure in the case without differential diffusion preheat and ignite the fuel stream earlier, causing a 30\% reduction in the cold jet trail. While on the other hand, the early ignition is unfavorable since it will influence the mass capture and even may causing unstart. In the case with differential diffusion, the high-temperature (above $2500 \mathrm{~K}$ ) region starts after the combustion injection and fills the whole combustor. In the case without differential diffusion, the main heat release region indicated by the high temperature starts before the combustor injection, and the heat is released in a more extended region covering both the isolator and combustor. It is the early heat release that causes the higher pressure rise from the secondary peak to the double peaks in Figure 3 (a). From the distribution of the main product $\mathrm{H}_{2} \mathrm{O}$, the initial combustion reaction starts at a far downstream location of the inlet section, while the combustion reacting occurs immediately from the inlet injection. The combustion seems to be closer to equilibrium for the unity-Lewis case, as indicated by the more productive $\mathrm{H}_{2} \mathrm{O}$ distribution inside the nozzle. $\mathrm{OH}$ is an important intermediate species in the chain branching of the hydrogen-oxygen reaction scheme, because there are more than half, 18 elementary reactions involve it in the total 33 steps. The high $\mathrm{OH}$ concentration in the diffusive interface between the fuel stream and the airflow near the bodyside wall indicates the ongoing nonequilibrium oxidation process there, while the low $\mathrm{OH}$ concentration in the combustor and nozzle indicates the near-equilibrium status. There are $\mathrm{OH}$ and $\mathrm{H}_{2} \mathrm{O}$ before the cowlside notch, suggesting that part of the hydrogen has been convected from the combustor by the pressure-rise-induced backflow. The Mach number distribution is visually similar in the downstream after the combustor injection; however, the ignorance of differential diffusion has observably reduced the overall Mach number in the inlet to be below 6, especially in the region between the inlet injection and the cowlside leading edge. The location and angle of the primary oblique shock wave generated by the cowlside leading edge are less affected by the differential diffusion since the mixing has not started.

Figures $4(\mathrm{k})$-(p) shows the mixing and combustion-related indices calculated from the instantaneous flow fields. The turbulent scalar mixing problem characterizes the rate of mixing at the molecular level, which is proportional to the square gradient of the scalar $\mathrm{Ns}=\mathrm{D}_{\xi}|\nabla \xi|^{2}$. Its conditional value represents the diffusion rate across the iso-surface of a specified mixture fraction point. It is generally considered that the turbulent scalar dissipation rate is an essential quantity in the description of the scalar evolution. However, previous analysis has pointed out that the characteristic time scale of scalar diffusion is much longer than the convection time scales in supersonic flows [57], and the supersonic mixing is considered to be dominant by the momentum exchange between the fuel stream and the airflow. A higher scalar dissipation rate close to the extinction limit may prohibit the autoignition. In the current study, the high scalar dissipation rate mainly distributing in the fuel jet trail is of the order of $10 \mathrm{~s}^{-1}$, which is far less than the extinction strain rate of the order of $10^{3} \mathrm{~s}^{-1}$ [59]; therefore fluctuations of the quantity caused by the turbulence have weak influence on the combustion process. In turbulent combustion, only a thin region around the reaction zone is governed by molecular transport, whereas unity Lewis numbers can be assumed since turbulent transport is predominant in most of the mixing region. Therefore, the scalar dissipation rate is weakly influenced by the differential diffusion effect.

Figures $4(\mathrm{~m})$-(n) show the Takeno Flame Index (TFI) [60] to distinguish the premixed (TFI $\geq 0$ ) and non-premixed $(\mathrm{TFI}<0)$ regions. In reference to Figures $4(\mathrm{e})-(\mathrm{h})$, the fuel has been premixed with the air before the reactions take place in the fuel jet trails, especially remarkable for the combustor-injected fuel stream. In the constant-area combustor, the entrainment of the air by large-scale vortex motions results in wavelets-like well-mixed regions of vortex size. Usually, those premixed regions are favorable for the flame holding of their neighbor non-premixed regions through providing ignition source and farming radicals. There is a unique phenomenon for the premixed regions in hypersonic combustion, that is the premixed regions are not separated as in subsonic flames [60] but appear as end-to-end connected strips. In addition, the area of premixed regions seems to overwhelm that of non-premixed regions. It suggests that the short convection time does not allow a complete burning even under well-mixed conditions, high temperatures ( $\geq 2000 \mathrm{~K})$, and for hydrogen with high reactivity. That is why a much longer scramjet combustor is usually required for high-Mach flights to provide sufficient flow residence time. The magnitude of TFI denotes the supplying rate of fuel and oxygen by molecular diffusion, which is proportional to the fuel and oxygen gradients. High-rate reactions quickly consume both the fuel and oxygen and tend to enhance the TFI magnitude.

Chemical Explosives Mode Analysis (CEMA) was conducted to distinguish the explosive mode (CEMA $>0 \mathrm{~s}^{-1}$ ) and equilibrium-evolving mode $\left(\mathrm{CEMA}<0 \mathrm{~s}^{-1}\right)$. CEMA is obtained from the eigendecomposition of the chemical source term Jacobian, whose positive eigenvalues define explosive modes with a characteristic timescale $\lambda_{i}^{-1}$ and the maximum one, i.e., the CEMA variable defines the fastest explosive mode. Figures 4 (o)-(p) shows the signed logscaling of the CEMA variable, sign (CEMA) $\times \log _{10}(1+\mid$ CEMA $\mid)$, where a minimum of $1 \mathrm{~s}^{-1}$ is added to filter out the chemically inactive zone denoted by $\mid$ CEMA $\mid<1$. From the current modeling, no detonation region of significant 
size has been identified in the reacting field, whereas the negative CEMA denotes slow chemistry gradually evolving towards equilibrium in most of the flow field. The detonation mode usually occurs in the transient ignition process, however, from the analysis of TFI, the ignition regions in hypersonic combustion has been stretched by the high-speed flow to be thin yet long, thus significantly relaxing the reaction progress and explosiveness. The post-ignition and diffusion-controlled regions usually have negative CEMA, shown in Figures 4 (o)-(p) as the trail regions with the lowest CEMA $<-7 \mathrm{~s}^{-1}$. The post-ignition region starts more upstream without differential diffusion, probably because the ignition distance has been considerably shortened by the high temperature near the inlet injector. Note that the nonequilibrium air chemistry has been incorporated in this study, the incoming air before any fuel injection still has non-zero values.

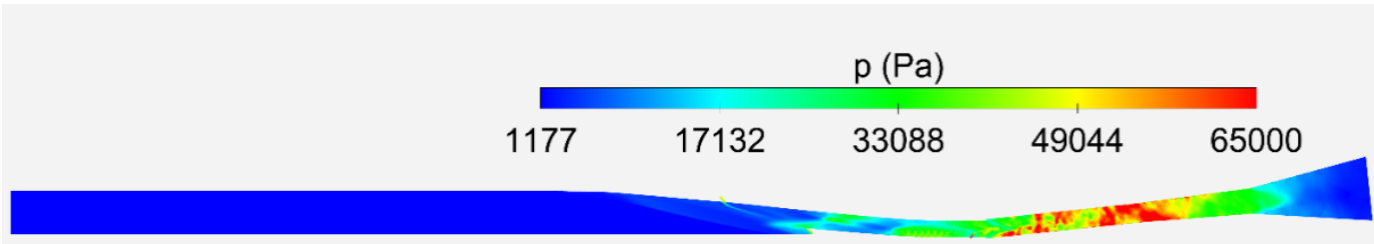

(a)

(b)
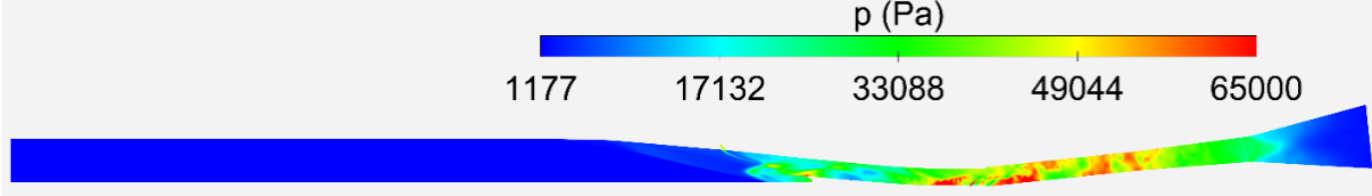

(c)
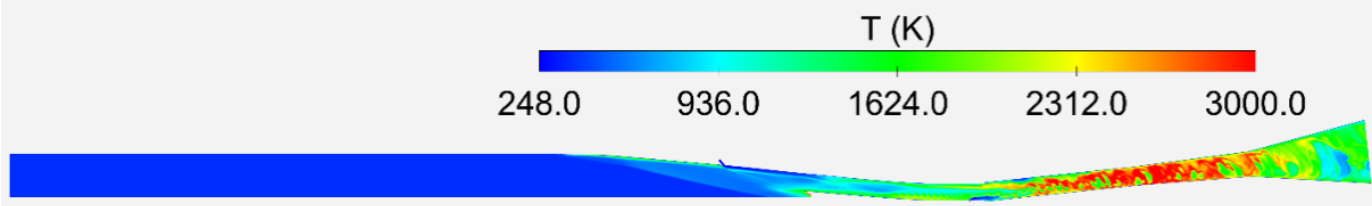

(d)
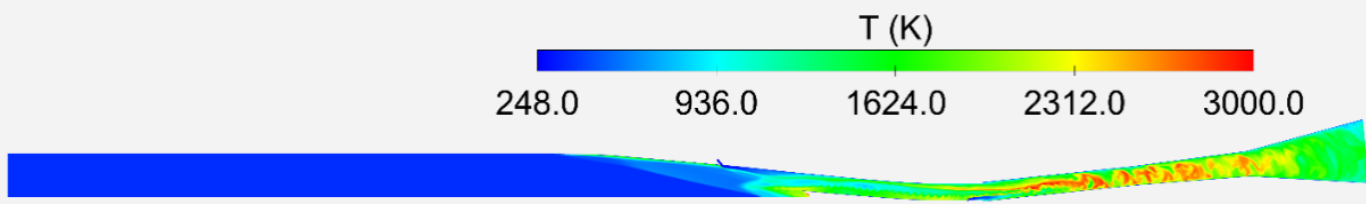

$\mathrm{H} 2 \mathrm{O}$

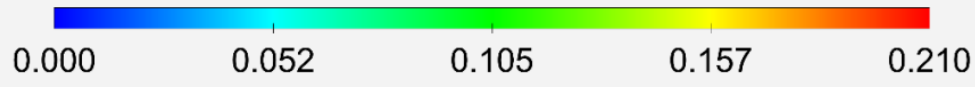

(e)

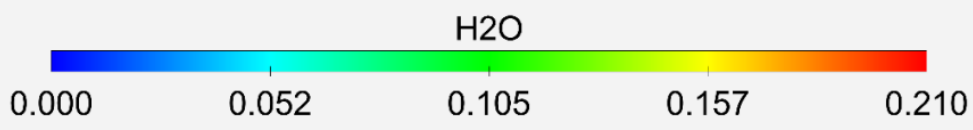

(f) 


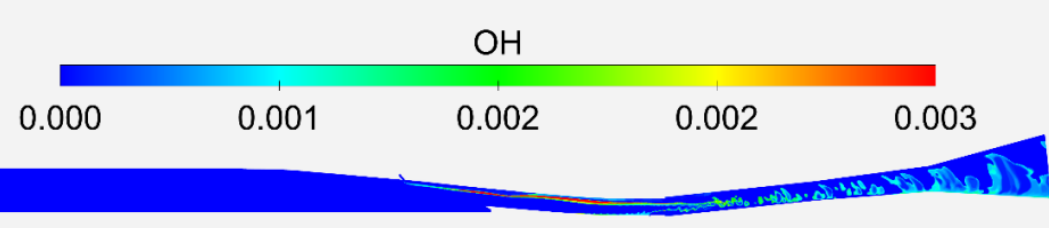

(g)

(h)
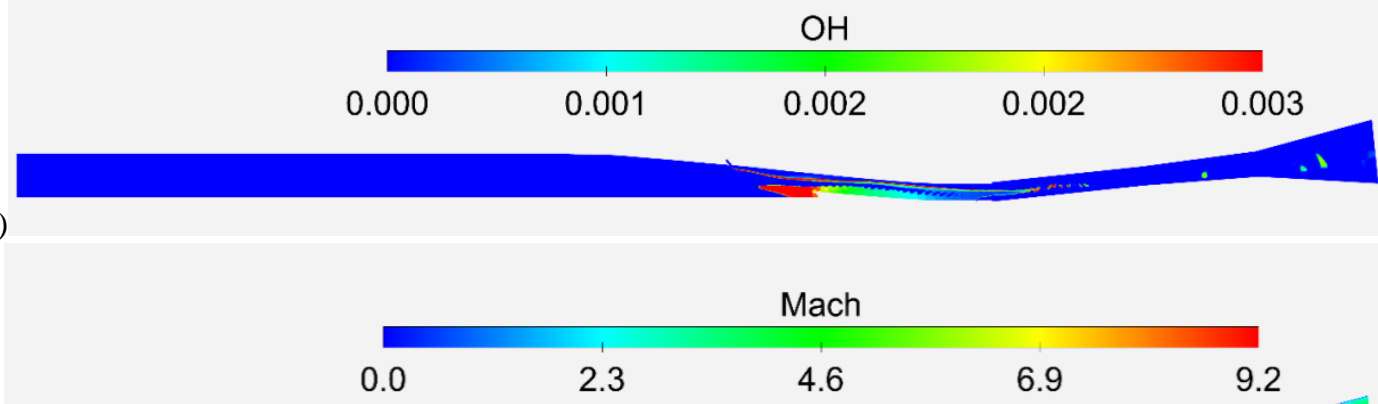

(i)

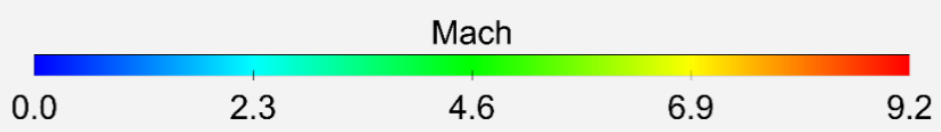

(j)

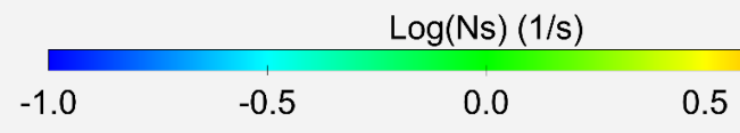

(k)

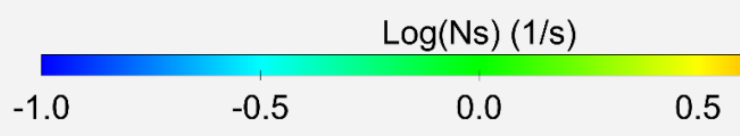

(1)

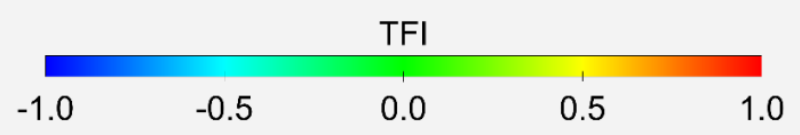

(m)

(n)

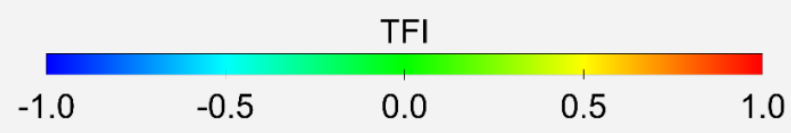




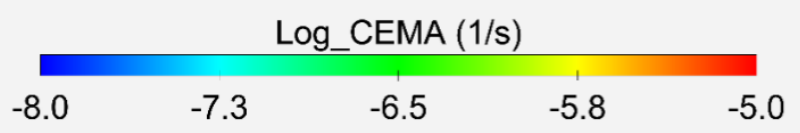

(o)

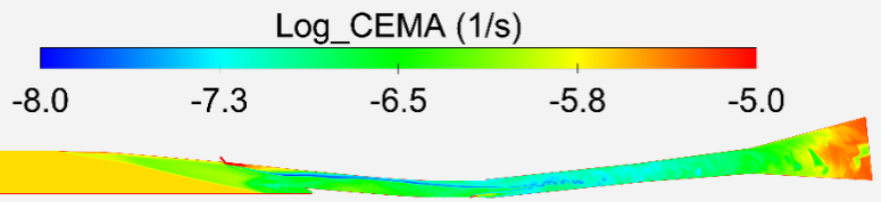

(p)

Figure 4. Contours on the centerplane along the streamwise direction for (a)-(b) pressure, (c)-(d) temperature, (e)-(f) H2O mass fraction, (g)-(h) OH mass fraction, (i)-(j) Mach number, (k)-(l) log-scaling of scalar dissipation rate, (m)-(n) Takeno flame index (TFI), (o)-(p) signed log-scaling of CEMA

Figure 5 shows the quasi-one-dimensional indices along the flow path to evaluate the mixing and combustion performance of the REST hypersonic combustor. The coefficients of mixing, combustion, and total pressure loss were calculated following the similar approaches in [57], except for some minor changes in the calculations of reactable and reacted fuel. The time-averaged mixing efficiency is calculated as,

with

$$
\begin{gathered}
\eta_{\text {mix }}=\frac{1}{n} \sum_{n} \frac{\dot{m}_{\text {fuel,reactable }}}{\dot{m}_{\text {fuel,total }}}=\frac{1}{n} \sum_{n} \frac{\int\left(\rho \vec{u} Y_{f, \text { react }}\right) \cdot d \vec{A}}{\int\left(\rho \vec{u} Y_{f}\right) \cdot d \vec{A}} \\
Y_{f, \text { react }}=\min \left(Y_{H}, Y_{o} / s\right)
\end{gathered}
$$

where $\dot{m}_{f u e l, \text { total }}$ is the total fuel mass flow rate, $\dot{m}_{f u e l, m i x e d}$ is the mass flow rate of reactable fuel that has been well mixed locally, $Y_{H}$ is the mass fraction of $\mathrm{H}$ element, $Y_{O}$ is the mass fraction of the $\mathrm{O}$ element; $s$ is the mass stoichiometric ratio in the global reaction $v_{f}$ Fuel+ $v_{o}$ Oxygen $\rightarrow$ Products and is defined as $s=v_{o} W_{o} Y_{f}^{0} / v_{f} W_{f} Y_{o}^{0}$, where $v_{f}$ and $v_{o}$ are the coefficients corresponding to fuel and oxidizer, $W_{f}$ and $W_{o}$ are the molecular weights of the fuel and oxidizer, $Y_{f}^{0}$ and $Y_{o}^{0}$ are the initial mass fractions of fuel and oxidizer in the fuel and oxidizer streams. Note that $Y_{f}$ is derived from the element fraction to adapt Eq. (14) for bot non-reacting and reacting cases. Combustion efficiency is calculated as the ratio of the fuel that has been completely converted to the final products, e.g., $\mathrm{H}_{2} \mathrm{O}$ :

$$
\eta_{\text {comb }}=\frac{1}{n} \sum_{n} \frac{\left[\frac{1}{v_{H 2 O}} \int\left(\rho \vec{u} Y_{H 2 O}\right) \cdot d \vec{A} / W_{H 2 O}\right]_{\text {inlet }}^{x}}{\frac{1}{v_{\text {fuel }}} \dot{m}_{\text {fuel,total }} / W_{\text {fuel }}}
$$

where the subscript inlet denotes variables on the air inlet plane, the surface integration is performed on each crosssection at different streamwise locations, $Y_{\mathrm{H} 2 \mathrm{O}}$ is the mass fraction of $\mathrm{H}_{2} \mathrm{O}, W_{\text {fuel }}$ and $W_{\mathrm{H}_{2} \mathrm{O}}$ are the molecular weights of the fuel and $\mathrm{H}_{2} \mathrm{O}, v_{\text {fuel }}$ and $v_{\mathrm{H} 2 \mathrm{O}}$ are the stoichiometric coefficients of the fuel and $\mathrm{H}_{2} \mathrm{O}$. The total pressure loss is calculated as,

$$
\eta_{P_{t}}=1-\frac{1}{n} \sum_{n} \frac{\int\left(\rho \vec{u} P_{t, x}\right) \cdot d \vec{A}}{\int\left(\rho \vec{u} P_{t, i n l e t}\right) \cdot d \vec{A}}(16)
$$

where $P_{t, x}$ and $P_{t, \text { inlet }}$ are the total pressure at the streamwise location $x$ and the air inlet plane, respectively. From Figure 5 (a), the mixing efficiency before and after $\mathrm{x}=1.015 \mathrm{~m}$ corresponds to the mixing behavior of the inlet and combustor injections, respectively. For the case with differential diffusion, more than half, $68.5 \%$ of the inlet injection has been mixed before encountering the combustor injection; the final mixing efficiency at the nozzle outlet is $90.3 \%$, which is satisfactory. If without differential diffusion, the mixing efficiency is slightly higher than the case with differential diffusion for the inlet injection stage and becomes lower for the combustor injection stage. This suggests that the stronger shock waves in the case without differential diffusion may help to enhance the mixing. Under the good mixing and favorable conditions (higher temperature and pressure), the combustion efficiency in the case without differential diffusion is initially higher, but the final value is $6 \%$ lower than the value of $84 \%$ in the case with differential diffusion. The case with differential diffusion obtains a final total pressure loss of $95 \%$, while the strong shock waves in the case without differential diffusion cause more substantial total pressure loss approaching $99 \%$. The total pressure loss can be caused by skin friction, shock waves, and heat addition. The skin-friction drag and wave 
(or pressure-related) drag comprise the total drag, whose reduction is especially important in improving the thrust of high-Mach scramjets. The total pressure loss implies that a considerable part of the available propulsive energy is transformed into heat, and to the induced vortices of the flow, which are finally converted to energy as well. The small nonmonotonicity in the coefficients the mixing, combustion, and total pressure loss are caused by the flow unsteadiness and local backflow. The impulse force function in the streamwise direction, defined as the summation of pressure force and momentum flux $\mathrm{I}=\mathrm{pA}+\rho \mathrm{u}^{2} \mathrm{~A}$, can measure the streamwise force according to the conservation of momentum $\mathrm{F}_{b x}=\Delta I$. Here the streamwise momentum contributed by the fuel addition is ignored since the injection direction is nearly normal to the streamwise diction, and the mass flow rate of fuel is negligible compared with the air stream. The momentum conservation is not valid for the flow from $\mathrm{x}=0.5$ to $0.84 \mathrm{~m}$, because part of the incoming air slips away from the inlet cowlside. In the inner part of the inlet and the isolator from $\mathrm{x}=0.84$ to $1.0 \mathrm{~m}$, the reduction of impulse force indicates that the net thrust is negative. The geometry is expanding for the combustor and nozzle since $x=1.0 \mathrm{~m}$, the increase in the impulse force demonstrates that the thrust provided by the pressure force exceeds the viscous drag (wall friction) to gain a net thrust in the two sections. The incorporation of the differential diffusion effect gains more net thrust in the combustion and nozzle sections. A more accurate determination of the net thrust is by direction surface integration over the internal walls. Defining that a drag force has a negative magnitude, and a thrust force has a positive magnitude, the friction drag is $-26 \mathrm{~N}$, while the pressure thrust is $+30 \mathrm{~N}$, and the total net thrust is $+4 \mathrm{~N}$. Although a phenomenal net thrust has been attained, the large drag force underscores the importance of skin-friction reduction techniques in producing a viable hypersonic vehicle. From the impulse force distribution, it is clear that the main burden in the drag reduction lies in the inlet section, where both the pressure drag and viscous drag are in comparable magnitude with the thrust force produced in the combustor and nozzle.

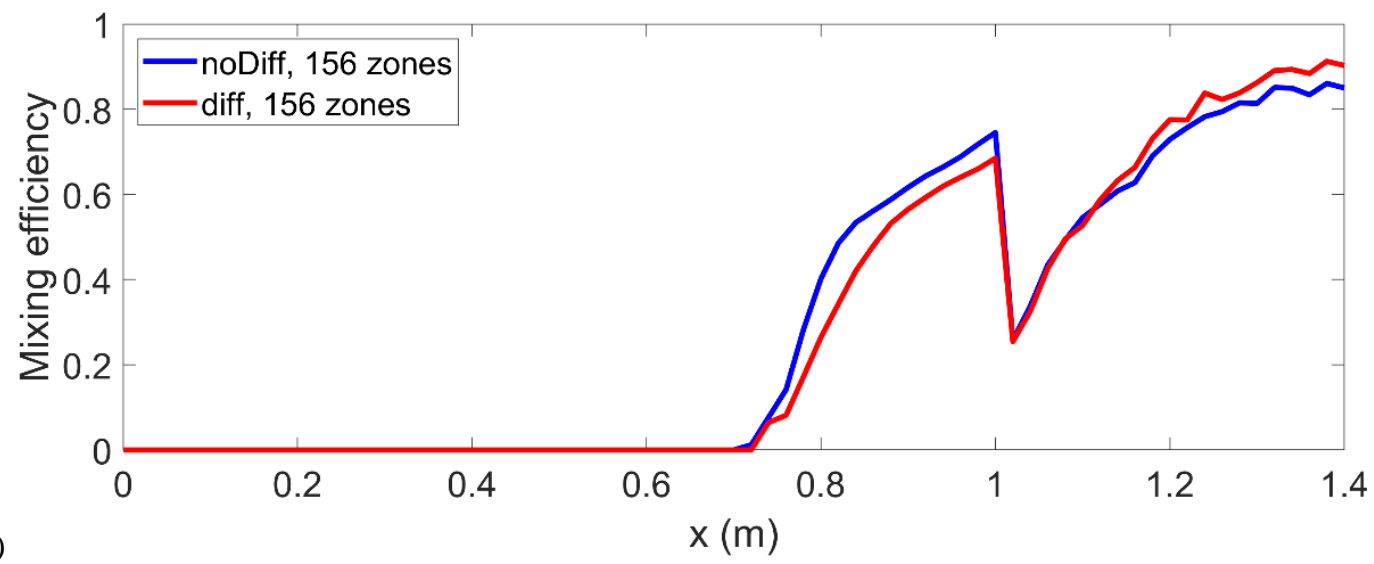

(a)

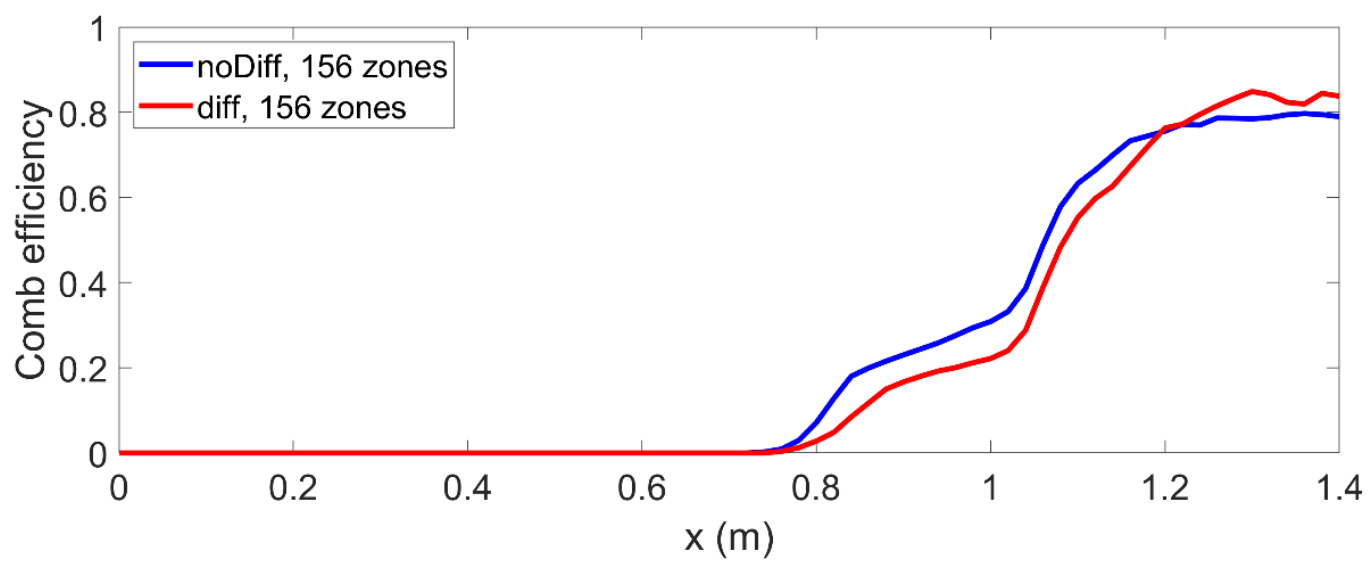




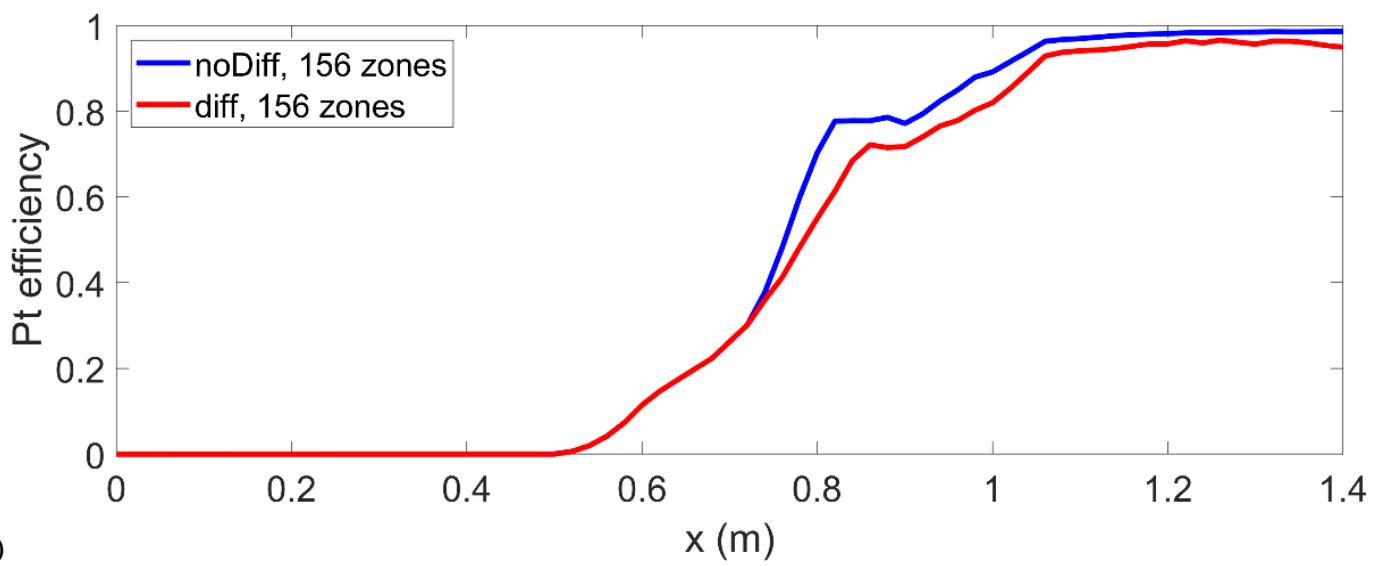

(c)

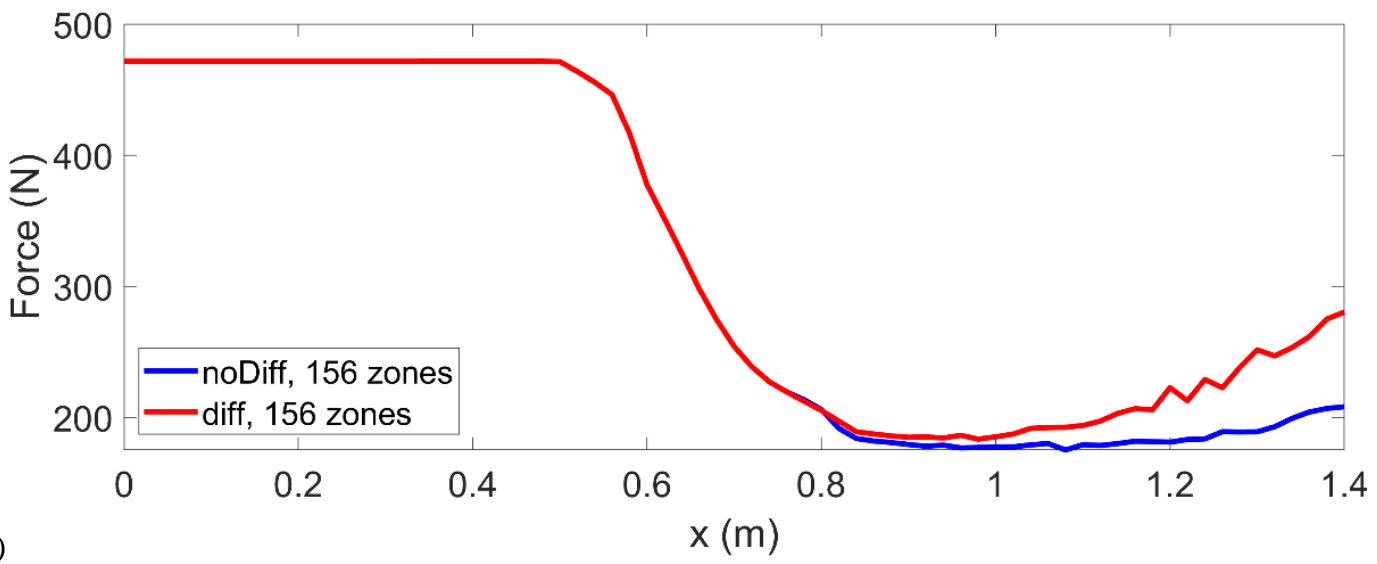

(e)

Figure 5. Quasi-one-dimensional indices along the flow path, (a) mixing efficiency, (b) combustion efficiency, (c) total pressure loss coefficient, (d) streamwise impulse force

The main idea of DZFM is to divide the whole combustion field into a finite number zones and assign a local flamelet to each zone. As seen, the prediction is influenced by the zone division. By grouping the whole field into a single flamelet zone, DZEM degrades into the conventional unsteady flamelet model [61]. Under the most extreme condition, the zone division is refined to a level close to the CFD meshing, DZFM can be considered identical to the traditional full-transport finite-rate chemistry models, e.g., PaSR, since the chemistry is solved zone by zone and the spatial transport of species are solved across the whole domain. However, as the zone division is refined, a zone independence behavior should be achieved, thus through configuring an optimal zone division, one can achieve accurate yet highly efficient modelings. Figure 6 compares the prediction of pressure by different zone discretization schemes. In this study, the spatial discretization is achieved by firstly equidistantly dividing the computational domain into swathes along the streamwise direction, and then further dividing each swath into 91 layers according to the 1 FTT moving-window-averaged mixture fraction field. Because the quasi-averaged mixture fraction field will evolve with the flow, the zone division is constantly updated to ensure that each zone corresponds to a narrow bin in the mixture fraction space. From the comparison, the zone schemes of $1 \times 91$ and $39 \times 91$ considerably underestimate the peak values, while the $78 \times 91$ zone scheme shows small but noticeable discrepancies. The schemes with streamwise discretization numbers larger than 156 show close predictions for both the bodyside and cowlside. Figure 7 shows the mixing and combustion efficiencies predicted by different zone discretization schemes. Only the $1 \times 91$ zone scheme shows small discrepancies with the others, which overlap with each other with an indistinguishable discrepancy. Compared with the discrepancies between different zone schemes, the ignorance of differential diffusion causes a more noticeable difference. 

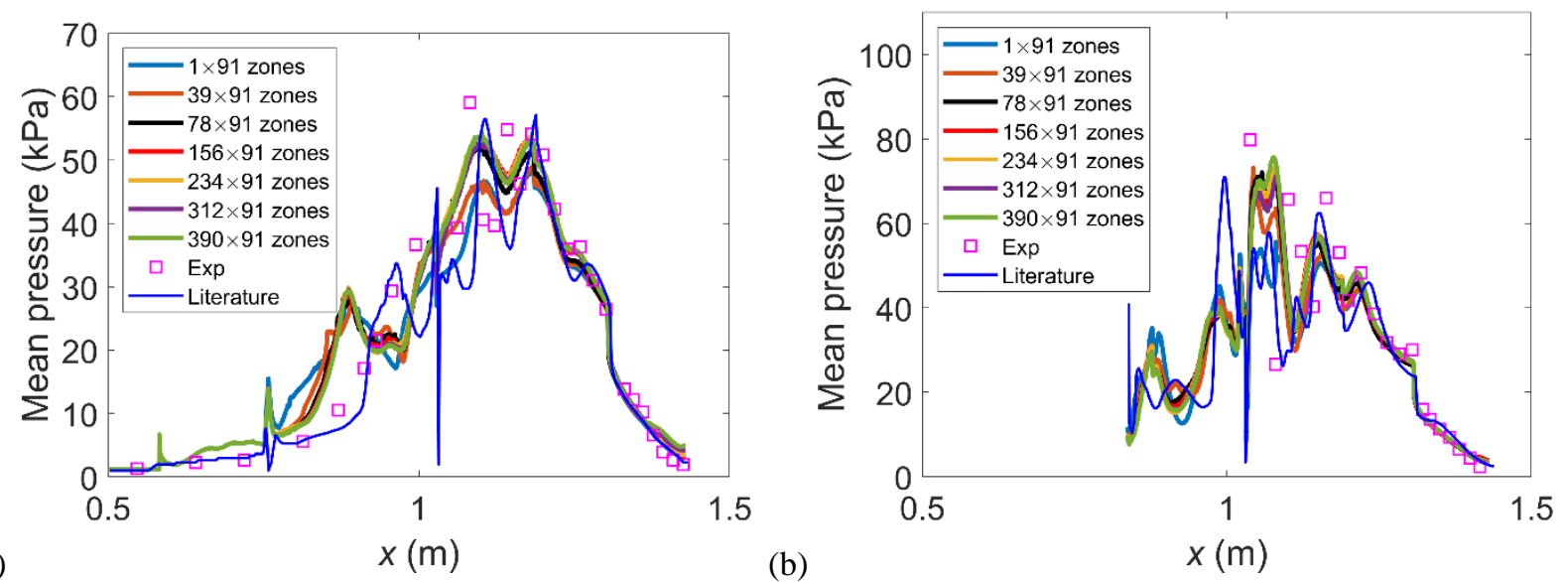

Figure 6. Pressure predicted by different discretization numbers of flamelet zones on the (a) bodyside and (b) cowlside
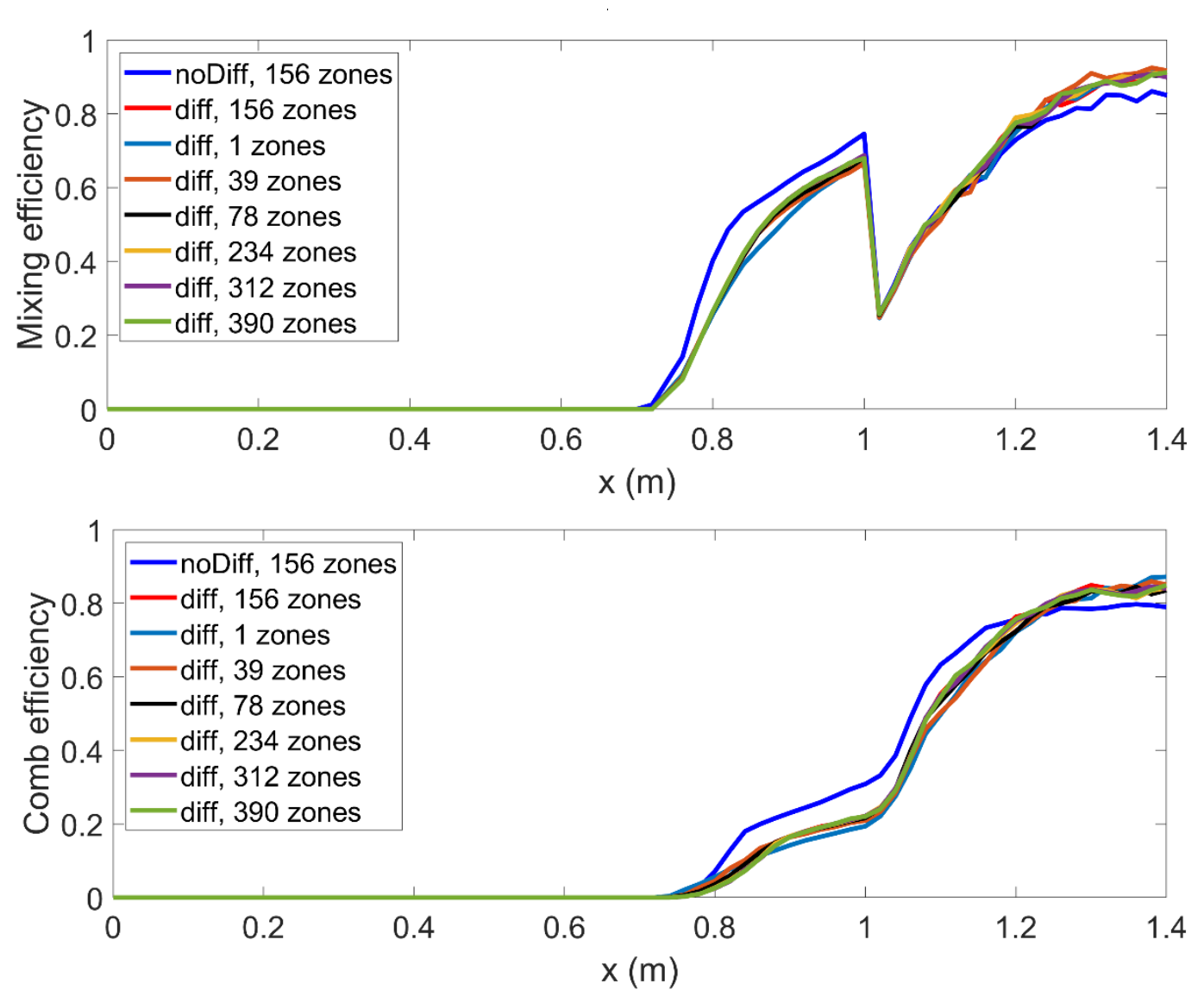

Figure 7. (a) Mixing and (b) combustion efficiencies predicted by different zone division schemes

Figure 8 shows the contour of the $\mathrm{O}$ atom, which plays the primary chaining role in producing $\mathrm{OH}$ and is a good indication of the initial reactions. The major drawback of using a single global flamelet zone is that the upstream mixture may be artificially "ignited" by the downstream burnt mixture since they share the same flamelet under burnt status. From Figure 8 (a), the reaction starts early because the upstream flow inherits the downstream reaction status. By further increasing the streamwise zone division, the upstream and downstream interacts only through the convective exchange of flamelet variables across the zone boundaries, as the way the convection of radicals aids ignition in the full-transport combustion models. The reaction inside the fuel trail also starts more upstream for the 
$39 \times 91$ scheme than the cases with more streamwise discretization, which are all similar.

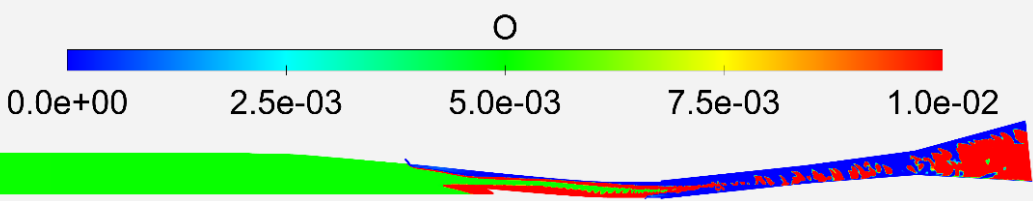

(a)

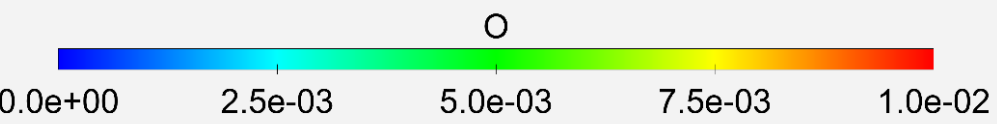

(b)
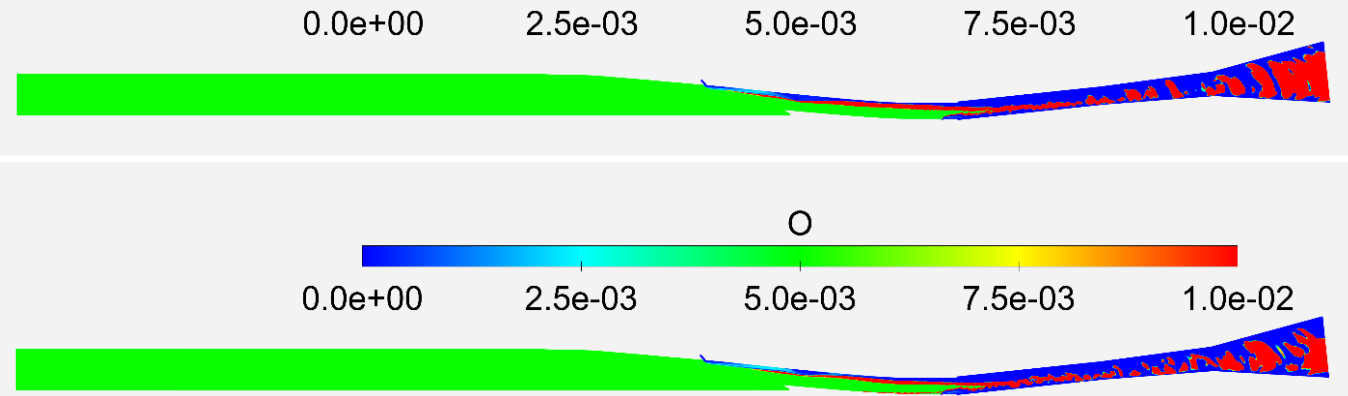

(c)

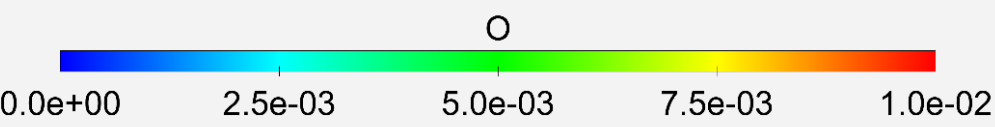

(d)

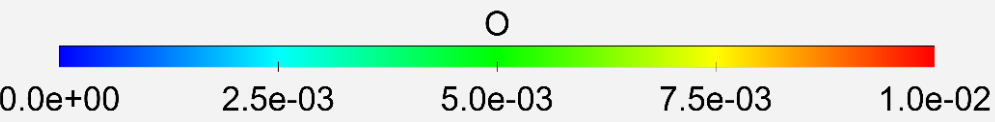

(e)

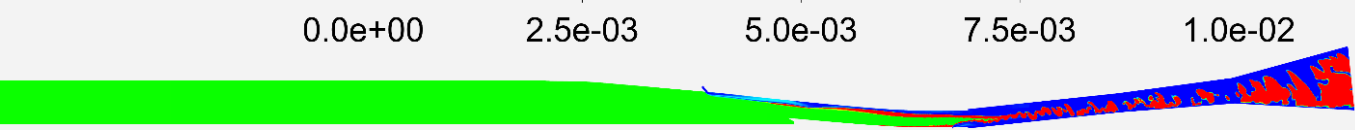

O

$0.0 e+00 \quad 2.5 e-03 \quad 5.0 e-03 \quad 7.5 e-03 \quad 1.0 e-02$

(f)

(g)

Figure 8. Instantaneous contours of $\mathrm{O}$ mass fraction predicted by different zone division schemes, (a) $1 \times 91$ zones, (b) $39 \times 91$ zones, (c) $78 \times 91$ zones, (d) $156 \times 91$ zones, (e) $234 \times 91$ zones, (f) $312 \times 91$ zones, (g) $390 \times 91$ zones 


\section{Conclusions}

The internal and external coupled flow for the full-scale REST hypersonic combustor was modeled by using large eddy simulation and a DZFM model. The pressure prediction is generally comparable with the measurements. For the bodyside, both the current and previous predictions exhibit double peaks. The ignorance of differential diffusion causes higher pressure rise in the inlet and isolator for the bodyside, while the unobvious influence on the pressure in the combustor and nozzle since where complete mixing has been achieved. Without differential diffusion, the disturbance of the incoming flow by the inlet fuel injection is stronger; thus, the pressure raised by the bow shock wave and the subsequent reflected shock waves inside the inlet and isolator is remarkably higher. The mass capture of the engine in the current prediction is $57 \mathrm{~g} / \mathrm{s}$ with differential diffusion, and $55 \mathrm{~g} / \mathrm{s}$ without differential diffusion, both are close to the $59.35 \mathrm{~g} / \mathrm{s}$ in the previous prediction. The inlet injection remains a near 10-cm long trail from the injector port before being visually diffused. The high temperature and pressure in the case without differential diffusion preheat and ignite the fuel stream earlier, causing a 30\% reduction in the cold jet trail.

In the constant-area combustor, the entrainment of the air by large-scale vortex motions results in wavelets-like well-mixed regions of vortex size. Unlike in subsonic flames, the premixed regions appear as end-to-end connected strips, indicating that a complete burning cannot be attained even under well-mixed conditions, high temperatures $(\geq$ $2000 \mathrm{~K}$ ), and for hydrogen with high reactivity. Therefore it is usually concluded that a much longer scramjet combustor is required for high-Mach flights to provide sufficient flow residence time. Chemical Explosives Mode Analysis (CEMA) identifies no detonation region of significant size in the reacting field, whereas the negative CEMA denotes a slow-chemistry post-ignition and diffusion-controlled modes in most of the flow field. The ignition regions in hypersonic combustion have been stretched by the high-speed flow to be thin yet long, thus significantly relaxing the reaction progress and explosiveness.

The final mixing efficiency at the nozzle outlet is $90.3 \%$, and the final combustion efficiency is $84 \%$. A total pressure loss approaching $95 \%$ is arrived with differential diffusion, while $99 \%$ if without differential diffusion. A phenomenal net thrust pf $+4 \mathrm{~N}$ has been attained, with The friction drag is $-26 \mathrm{~N}$, and the pressure thrust is $+30 \mathrm{~N}$. The large drag force underscores the importance of skin-friction reduction techniques in producing a viable hypersonic vehicle. The main burden in the drag reduction lies in the inlet section, where both the pressure drag and viscous drag are in comparable magnitude with the thrust force produced in the combustor and nozzle.

A sensitivity analysis of the DZFM zone discretization was conducted. The zone schemes of $1 \times 91$ and $39 \times 91$ considerably underestimate the peak pressure values and predict early reactions, while the schemes with streamwise discretization numbers larger than 156 show indistinguishable predictions. Compared with the discrepancies between different zone schemes, the ignorance of differential diffusion causes a more prominent difference.

\section{Acknowledgments}

The research was supported by Training Program of the Major Research Plan of the National Natural Science Foundation of China (Grant No. 91641110), National Key Research and Development Program of China (2019YFB1704200), and the Open founding of National Key Laboratory of Science and Technology on Aero-Engine Aero-Thermodynamics (Grant No. 6142702180307). The authors are also grateful to the National Supercomputer Center in Tianjin for providing the computational resource.

\section{References}

1. Yao, W., "Kerosene-Fueled Supersonic Combustion Modelings Based on Skeletal Mechanisms," Acta Mechanica Sinica, Vol. 35, 2019, pp. 1155-1177. doi: 10.1007/s10409-019-00891-w

2. $\quad$ Smart, M. K., and Tetlow, M. R., "Orbital Delivery of Small Payloads Using Hypersonic Airbreathing Propulsion," Journal of Spacecraft and Rockets, Vol. 46, No. 1, 2009, pp. 117-125. doi: 10.2514/1.38784

3. Mehta, U. B., "Strategy for Developing Air-Breathing Aerospace Planes," Journal of Aircraft, Vol. 33, No. 2, 1996, pp. 377-385. doi: 10.2514/3.46948

4. Marshall, L. A., Bahm, C., Corpening, G. P., and Sherrill, R., "Overview with Results and Lessons Learned of the X-43a Mach 10 Flight." AIAA 2005-3336, 16-20 May 2005.

5. Weber, R. J., and Mackay, J. S., "An Analysis of Ramjet Engines Using Supersonic Combustion," Lewis Flight Propulsion Laboratory, Technical note 4386, Washington D C, 1958.

6. S Smart, M. K., "Design of Three-Dimensional Hypersonic Inlets with Rectangular-to-Elliptical Shape Transition," Journal of Propulsion and Power, Vol. 15, No. 3, 1999, pp. 408-416. doi: 10.2514/2.5459 
7. Gollan, R., and Ferlemann, P., "Investigation of Rest-Class Hypersonic Inlet Designs." 11 - 14 April 2011. doi: $10.2514 / 6.2011-2254$

8. Smart, M. K., "Experimental Testing of a Hypersonic Inlet with Rectangular-to-Elliptical Shape Transition," Journal of Propulsion and Power, Vol. 17, No. 2, 2001, pp. 276-283. doi: 10.2514/2.5774

9. $\quad$ Barth, J. E., Wheatley, V., and Smart, M. K., "Effects of Hydrogen Fuel Injection in a Mach 12 Scramjet Inlet," AIAA Journal, Vol. 53, No. 10, 2015, pp. 2907-2919. doi: 10.2514/1.J053819

10. Gardner, A. D., Paull, A., and McIntyre, T. J., "Upstream Porthole Injection in a 2-D Scramjet Model," Shock Waves, Vol. 11, 2002, pp. 369-375.

11. Chan, W. Y. K., Razzaqi, S. A., Turner, J. C., Suraweera, M. V., and Smart, M. K., "Freejet Testing of the Hifire 7 Scramjet Flowpath at Mach 7.5," Journal of Propulsion and Power, Vol. 34, No. 4, 2018, pp. 844-853. doi: 10.2514/1.B36652

12. Curran, D., Wheatley, V., and Smart, M., "Investigation of Combustion Mode Control in a Mach 8 Shape-Transitioning Scramjet," AIAA Journal, Vol. 57, No. 7, 2019, pp. 2977-2988. doi: 10.2514/1.J057999

13. Suraweera, M. V., and Smart, M. K., "Shock-Tunnel Experiments with a Mach 12 Rectangular-to-Elliptical ShapeTransition Scramjet at Offdesign Conditions," Journal of Propulsion and Power, Vol. 25, No. 3, 2009, pp. 555-564. doi: $10.2514 / 1.37946$

14. Doherty, L. J., Smart, M. K., and Mee, D. J., "Experimental Testing of an Airframe-Integrated Three-Dimensional Scramjet at Mach 10," AIAA Journal, Vol. 53, No. 11, 2015, pp. 3196-3207. doi: 10.2514/1.J053785

15. Landsberg, W. O., Wheatley, V., Smart, M. K., and Veeraragavan, A., "Enhanced Supersonic Combustion Targeting Combustor Length Reduction in a Mach 12 Scramjet," AIAA Journal, 2019. doi: 10.2514/1.J057417

16. Barth, J. E., "Mixing and Combustion Enhancement in a Mach 12 Shape-Transitioning Scramjet Engine," PHD thesis, School ofMechanical and Mining Engineering, The University ofQueensland, 2014.

17. Dylan, J. W., and Michael, K. S., "Experimental Investigation of a Three-Dimensional Scramjet Engine at Mach 12," 20th AIAA International Space Planes and Hypersonic Systems and Technologies Conference, Glasgow, Scotland, 6-9 July, 2015. doi: doi:10.2514/6.2015-3650

18. Bricalli, M. G., Brown, L., Boyce, R. R., Gollan, R., Vanyai, T., and Pudsey, A. S., "Scramjet Performance with Nonuniform Flow and Swept Nozzles," AIAA Journal, 2019. doi: 10.2514/1.J056963

19. Tetlow, M. R., and Doolan, C. J., "Comparison of Hydrogen and Hydrocarbon-Fueled Scramjet Engines for Orbital Insertion," Journal of Spacecraft and Rockets, Vol. 44, No. 2, 2007, pp. 365-373. doi: 10.2514/1.24739

20. Lewis, M. J., "Significance of Fuel Selection for Hypersonic Vehicle Range," Journal of Propulsion and Power, Vol. 17, No. 6, 2001, pp. 1214-1221. doi: 10.2514/2.5866

21. Jr., J. A., "Hypersonic and High Temperature Gas Dynamics," New Yokr: McGraw-Hill, Inc., 1989.

22. Tanimizu, K., Mee, D. J., Stalker, R. J., and Jacobs, P. A., "Drag Force on Quasi-Axisymmetric Scramjets at Various Flight Mach Numbers: Theory and Experiment," Shock Waves, Vol. 19, No. 2, 2009, pp. 83-93. doi: 10.1007/s00193009-0194-x

23. Smart, M. K., and Trexler, C. A., "Mach 4 Performance of Hypersonic Inlet with Rectangular-to-Elliptical Shape Transition," Journal of Propulsion and Power, Vol. 20, No. 2, 2004, pp. 288-293. doi: 10.2514/1.1296

24. Smart, M. K., "How Much Compression Should a Scramjet Inlet Do?," AIAA Journal, Vol. 50, No. 3, 2012 , pp. $610-619$. doi: $10.2514 / 1 . j 051281$

25. Drayna, T. W., Nompelis, I., and Candler, G. V., "Hypersonic Inward Turning Inlets: Design and Optimization." AIAA 2006-297, 9-12 January 2006.

26. Clarke, D. K., Hassan, H. A., and Salas, M. D., "Euler Calculations for Multielement Airfoils Using Cartesian Grids," AIAA Journal, Vol. 24, No. 3, 1986, pp. 353-358. doi: 10.2514/3.9273

27. Piomelli, U., "Large-Eddy and Direct Simulation of Turbulent Flows," Introduction to Turbulence Modelling. Von Karman Institute, Belgium, , 2004.

28. Sankaran, V., Genin, F., and Menon, S., "Subgrid Mixing Modeling for Large Eddy Simulation of Supersonic Combustion," 42nd Aiaa Aerospace Sciences Meeting and Exhibit. American Institute of Aeronautics and Astronautics, 2004.

29. Yao, W., "On the Application of Dynamic Zone Flamelet Model to Large Eddy Simulation of Supersonic Hydrogen Flame," Internatinal Journal of Hydrogen Energy, 2020. doi: 10.1016/j.ijhydene.2020.05.189

30. Yao, W., and Fan, X., "Development of Zone Flamelet Model for Scramjet Combustor Modeling ". AIAA 2017-2277, 6-9 March 2017. doi: 10.2514/6.2017-2277

31. Yao, W., and Li, B., "Application of Dynamic Zone Flamelet Model to a Gh2/Go2 Rocket Combustor." AIAA 20193868, 19-22 August 2019. doi: 10.2514/6.2019-3868

32. Triantafyllidis, A., and Mastorakos, E., "Implementation Issues of the Conditional Moment Closure Model in Large Eddy Simulations," Flow Turbulence Combustion, Vol. 84, 2010, pp. 481-512.

33. Shur, M. L., Spalart, P. R., Strelets, M. K., and Travin, A. K., "A Hybrid Rans-Les Approach with Delayed-Des and Wall-Modelled Les Capabilities," International Journal of Heat and Fluid Flow, Vol. 29, 2008, pp. 1638-1649. doi: 10.1016/j.ijheatfluidflow.2008.07.0

34. Spalart, P. R., and Allmaras, S. R., "A One-Equation Turbulence Model for Aerodynamic Flows." AIAA-92-0439, 6-9 January 1992. doi: 10.2514/6.1992-439 
35. Jachimowski, C. J., "An Analysis of Combustion Studies in Shock Expansion Tunnels and Reflected Shock Tunnels," Langley Research Center, NASA Technical Paper 3224, Hampton, Virginia, 1992.

36. James, E. B., Dylan, J. W., Vincent, W., and Michael, K. S., "Tailored Fuel Injection for Performance Enhancement in a Mach 12 Scramjet Engine," 20th AIAA International Space Planes and Hypersonic Systems and Technologies Conference, Glasgow, Scotland, 6-9 July, 2015. doi: doi:10.2514/6.2015-3614

37. Kee, R. J., Rupley, F. M., and Miller, J. A., "Chemkin-Ii: A Fortran Chemical Kinetics Package for the Analysis of GasPhase Chemical Kinetics," Sandia National Laboratories 1989.

38. Chase, M. W., "Nist-Janaf Thermochemical Tables. (4th Ed.)," Journal of Physical and Chemical Reference Data, Vol. 9, No. 1-2, 1998, pp. 1-1952.

39. Bird, R. B., Stewart, W. E., and Lightfoot, E. N., "Viscosity and the Mechanisms of Momentum Transport," Transport Phenomena (2nd Edition). John Wiley \& Sons, New York, 2002, p. 27.

40. Weller, H. G., Tabor, G., Jasak, H., and Fureby, C., "A Tensorial Approach to Cfd Using Object Oriented Techniques," Computers in Physics, Vol. 12, No. 6, 1997, pp. 620-631. doi: 10.1063/1.168744

41. Lee, Y., Yao, W., and Fan, X., "Low-Dissipative Hybrid Compressible Solver Designed for Large Eddy Simulation of Supersonic Turbulent Flows," AIAA Journal, Vol. 56, No. 8, 2018, pp. 3086-3096. doi: 10.2514/1.J056404

42. Kurganov, A., and Tadmor, E., "New High-Resolution Central Schemes for Nonlinear Conservation Laws and Convection-Diffusion Equations," Journal of Computational Physics, Vol. 160, No. 1, 2000, pp. 241-282. doi: 10.1006/jcph.2000.6459

43. Pirozzoli, S., "Generalized Conservative Approximations of Split Convective Derivative Operators," Journal of Computational Physics, Vol. 229, No. 19, 2010, pp. 7180-7190. doi: 10.1016/j.jcp.2010.06.006

44. Wu, K., Li, X., Yao, W., and Fan, X., "Three-Dimensional Numerical Study of the Acoustic Properties of a Highly Underexpanded Jet." AIAA 2015-3572, 6-9 July 2015. doi: 10.2514/6.2015-3572

45. Li, X., Wu, K., Yao, W., and Fan, X., "A Comparative Study of Highly Underexpanded Nitrogen and Hydrogen Jets Using Large Eddy Simulation." AIAA 2015-3573, 6-9 July 2015. doi: 10.2514/6.2015-3573

46. Greenshields, C. J., Weller, H. G., Gasparini, L., and Reese, J. M., "Implementation of Semi-Discrete, Non-Staggered Central Schemes in a Colocated, Polyhedral, Finite Volume Framework, for High-Speed Viscous Flows," International Journal for Numerical Methods in Fluids, Vol. 38, No. 2, 2009, pp. 139-161. doi: 10.1002/fld.2069

47. Li, X., Yao, W., and Fan, X., "Large-Eddy Simulation of Time Evolution and Instability of Highly Underexpanded Sonic Jets," AIAA Journal, Vol. 54, No. 10, 2016, pp. 3191-3211. doi: 10.2514/1.J054689

48. Li, X., Zhou, R., Yao, W., and Fan, X., "Flow Characteristic of Highly Underexpanded Jets from Various Nozzle Geometries," Applied Thermal Engineering, Vol. 125, 2017, pp. 240-253. doi: 10.1016/j.applthermaleng.2017.07.002

49. Li, X., Fan, E., Yao, W., and Fan, X., "Numerical Investigation of Characteristic Frequency Excited Highly Underexpanded Jets," Aerospace Science and Technology, Vol. 63, 2017, pp. 304-316. doi: 10.1016/j.ast.2017.01.005

50. Lee, Y., Yao, W., and Fan, X., "A Low-Dissipation Solver Based on Openfoam Designed for Large Eddy Simulation in Compressible Flows." AIAA 2017-2444, 6-9 March 2017. doi: 10.2514/6.2017-2444

51. Li, X., Wu, K., Yao, W., and Fan, X., "A Comparative Study of Highly Underexpanded Nitrogen and Hydrogen Jets Using Large Eddy Simulation," International Journal of Hydrogen Energy, Vol. 41, No. 9, 2015, pp. 5151-5161. doi: 10.1016/j.ijhydene.2016.01.120

52. Yao, W., Wang, J., Lu, Y., Li, X., and Fan, X., "Full-Scale Detached Eddy Simulation of Kerosene Fueled Scramjet Combustor Based on Skeletal Mechanism." AIAA 2015-3579, 6-9 July 2015. doi: 10.2514/6.2015-3579

53. Wu, K., Zhang, P., Yao, W., and Fan, X., "Numerical Investigation on Flame Stabilization in Dlr Hydrogen Supersonic Combustor with Strut Injection," Combustion Science and Technology, Vol. 189, No. 12, 2017, pp. 2154-2179. doi: 10.1080/00102202.2017.1365847

54. Yao, W., Lu, Y., Li, X., Wang, J., and Fan, X., "Improved Delayed Detached Eddy Simulation of a High-Ma ActiveCooled Scramjet Combustor Based on Skeletal Kerosene Mechanism." AIAA-2016-4761, 25-27 July 2016. doi: 10.2514/6.2016-4761

55. Yao, W., Yuan, Y., Li, X., Wang, J., Wu, K., and Fan, X., "Comparative Study of Elliptic and Round Scramjet Combustors Fueled by Rp-3," Journal of Propulsion and Power, Vol. 34, No. 3, 2018, pp. 772-786. doi: arc.aiaa.org/doi/abs/10.2514/1.B36721

56. Wu, K., Yao, W., and Fan, X., "Development and Fidelity Evaluation of a Skeletal Ethylene Mechanism under ScramjetRelevant Conditions," Energy \& Fuels, Vol. 31, No. 12, 2017, pp. 14296-14305. doi: 10.1021/acs.energyfuels.7b03033

57. Yao, W., Lu, Y., Wu, K., Wang, J., and Fan, X., "Modeling Analysis of an Actively-Cooled Scramjet Combustor under Different Kerosene/Air Ratios," Journal of Propulsion and Power, Vol. 34, No. 4, 2018, pp. 975-991. doi: doi.org/10.2514/1.B36866

58. Yao, W., Wu, K., and Fan, X., "Influences of Domain Symmetry on Supersonic Combustion Modeling," Journal of Propulsion and Power, Vol. 35, No. 2, 2019, pp. 451-465. doi: 10.2514/1.B37227

59. Niklas, Z., Kevin, N.-B., and Christer, F., "Understanding Scramjet Combustion Using Les of the Hyshot Ii Combustor." 6-9 July 2015. doi: doi:10.2514/6.2015-3615

60. Yamashita, H., Shimada, M., and Takeno, T., "A Numerical Study on Flame Stability at the Transition Point of Jet Diffusion Flames," Proceeding of the Combustion Institute, Vol. 26, No. 1, 1996, pp. 27-34.

61. Pitsch, H., Chen, M., and Peters, N., "Unsteady Flamelet Modeling of Turbulent Hydrogen-Air Diffusion Flames," 27th Symposium (International) on Combustion, Vol. 27, No. 1, 1998, pp. 1057-1064. 
